
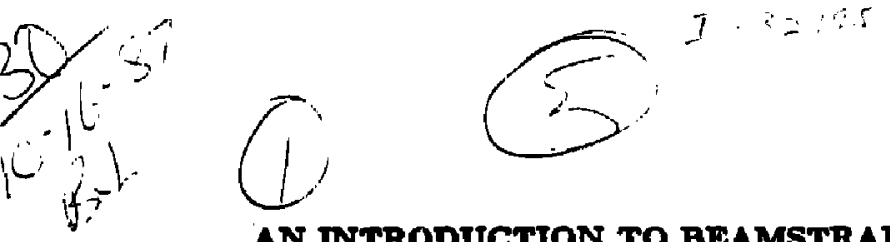

$D R \quad 0321-2$

SLAC - PUB - 4379

Auguat 19187

(A/E/T)

AN INTRODUCTION TO BEAMSTRAHUUNG AND DISRUPTION*

PISTN CAIEN

$\operatorname{coN} F-\$ 610108--6$

Stanford Linear Accelenator Center

Stenford University, Stanford, Cabiformin ofsos

SLAC-PUB -4379

TABIS OF CONTENTS

DE88 000708

1. INTRODUCTION .................... 2

2. DISRUPTION WITH NEGLIGIBLE BEAMSTRARLUNG . . . . 4

2.1 Focusing Effect and the Dieruption Parameter . . . . . . 4

2.2 Disruption Anglea . . . . . . . . . . . . T

2.3 Luminosity Enhencement Fector ........... 8

2.4 The Effects Due to Initial Emittance. . . . . . . . , 12

2.4.1 Effect on Luminonity Enhancennent . . . . . . . . 12

2.4 .2 Effect on Diaruption Angle .......... 15

3. BEAMSTRAHLUNG WITH NEGLIGIBLE DISEUPTION . . . . 16

3.1 The Nature of Beamatrahlung . . . . . . . . . 16

3.1.1 Collective Fields from Diacrete Sentering Contete ... 16

3.1.2 Presence of Both Electric and Megnetic Fivild . . . . 19

3.1.3 Finite Extents of the Fields . . . . . . . . . 20

3.2 Synchrotron Radination in a Serii-Uniform Pield . . . . 21

3.2.1 Brier-Katkov Approach . . . . . . . . . 21

3.2 .2 Formation Length and Grantulurity . . . . . . . 29

3.3 Synchrotron Radistion in a Varying Fiald . . . . . . 25

3.3.1 Head-Tail Symmetry and Gaveatian Correction . . . . 25

3.3.2 Short Magnets and Radiation Reduction . . . . . 29

3.4 Reduction of Quantum Beamutrahlung ......... . 30

3.4.1 First Beamstrahlung Reduction Factor ....... 30

3.4.2 Second Beamstrahlung Reduction Factor ...... 33

APPFNDR: QUANTUM FLUCTUATIONS IN BgAMSTRAFIUNG . . . . . . 37

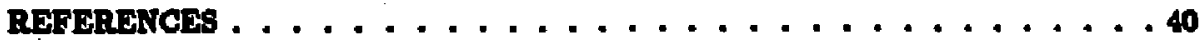

Lecture given at US-CBRU Joint Topical Course on Frontiese of Particle Beams;

South Padre Island, Texas, Oct. 23-29, 1986

+ Work oupported by tho Departiment of Energy, contract DE-ACOS - 765Fo0s15. 


\title{
AN INTRODUCTION TO BEAMSTRAHLUNG AND DISRUPTION
}

\author{
PISL CHEN \\ Stanford Linear Accelerator Center \\ Stanford Uniuersity, Stanford, Calijornia 84905
}

\section{INTRODUCTION}

To achieve enough luminosity for high energy physics experiments, it is inevitable to focus the colliding $e^{+} e^{-}$beams down to miniscule dimensions at the interaction point in linesr collidera. In the world's first of such accelerators, the Stanford Linear Collider (SLC), benm aise at the interaction point is designed to be $\sigma_{z}=\sigma_{y}=1.65 \mu \mathrm{m}$, and $\sigma_{z}=1 \mathrm{~mm}$ [1]. For the next generation of linear colliders at the range of $1 \mathrm{IzV}$ in center-of-moss energy the beam size would be even smaller. The high dennity of charged relativistic particles would provide strong electromagnetic fields viewed by the particles of the oncoming beam, while the particles in the same bunch have no effect among each other because of the cancellation of Lorents forces between the electric and the magnetic components to the accuracy of the order of $1 / \gamma$. The bending of particle trajectories under the infuence of these EM fieldu provided by the oncoming beam is called disruption. During bending particles would radiate, causing an energy los of the beam; this is called beamstratinge. Both effects are important to the design of linenr colliders $[2,3]$. .

In this lecture we review the current underatanding of the beam-beam interaction in $e^{+} e^{-}$ linear collider. Strictly spenking, the two effects, disuption and beamstrablung, during beambeam interaction are conpled. This is self-evident because without deflection there would be no radiation, and with radiation during bending the remaining trajectory of particles would not be the same. Fortunately, in a large range of beam parameters the average disruption angles are zather small, and the emission of hard photons are relatively rare. For these reasons the two effects can be isolated from each other to the first degree of accuracy, and our stody of the issuc can be greatly simplified. This happens also to be the development historically. In aec. 2 we discuss the effects associated with disruption with negligible beamstrahlung. Here, an important parameter, the disruption parameter $D$, is introduced. We then discuss the maximum and rma disruption angles. The analytic scaling lawe for $D>1$ and $D<1$ are then compared with simulation reultw. Next we invertigate the enhancement of luminosity due to disroption. Together with the aspect ratio $R \equiv \sigma_{z} / \sigma_{n}$, the two parameters define a scaling lay for luminosity enhancement, $H_{D 1}$, due to the mutual pinching of the $e^{+} e^{-}$bunches where the effective beam size $\sigma_{3} \sigma_{y}$ is reduced. In addition to the luminosity enhancement arised from the overall reduction of the beam size, there is a second source for the enhancement that comes from the extremely high particle density at the focal point inside the oncoming bnnch. This second enhancement, $H_{D 2}$, becomes dominant over $B_{D 1}$ when $D \gtrless 1$, and is a function of the initial emittance which is characterised by the parameter $A \equiv \sigma_{z} / \beta^{*}$, where $\beta^{*}$ is the $\beta$-function at the interaction point. 
Next we dincuse beamstrahlung with negligible disruption in sec. 3. First we review the nature of beammtrahlung by describing the novel features of the problem. These specifle features are then compared with the lmown radiation phenomens with emphnis on their aimilarities and differences. We argue that, in certain parameter range, the radintion mechaniam of beamntrahlung is agnchrotron radiation in nature. By this we menn the eminaion of a photon is induced by the interaction between the radiating particle and a collection of target particlea vis itu maeroscopic

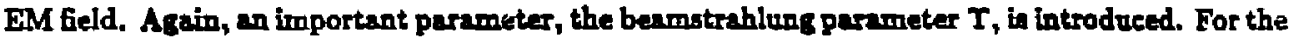
case $T<1$, typical energy of the photons is much smaller than the initial energy of the radiating particle and this is called the claseical regime. On the contrary, when $T>1$, photon tend to carry away a aubatentivl fraction of the radiating particle energ; thic in the quantum regime. For intermediate values of $T$, i.e, 0.1 S I S 100, the radiation is in the tranaition repime. We frut derive the synehrotron radiation intensities from a semi-omiform feld in the ehmieal and quentum regimes. These expreasions reproduce all the well-known formulas for a uniform feld. We then review the concept of radiation formation length $\ell_{R}$ and arge that the effect of granutarity of the target bunch is not observable in the quantum regima. Next we foeve on the fact that in the problem of beamotrahlung the target field is longitudinally inhomogeneous. To be correct it

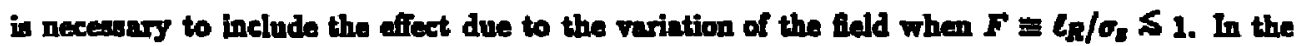
extreme limit where $F>1$, the radiation mechninm would depart from the eharecteriatico of aynchrotron radietion and transform into that of bremutralung.

The average fractional energs lose ( $)$ in beanotrahlong is then calcuinted explicitly. In

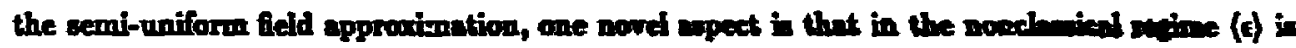
reduced" from what the chasical radiation formula would predict band on the want vine of T. The frot benmatrahlung rednetion factor $B_{Y I}$ i introduced to describ thie relative chnnge When the slope effect is included, we see a second betmitrahlons reduction effect, deveribed by $\boldsymbol{H}_{\mathrm{T} 3}$. The quantum fuctuation due to finite number of radlated photons in various beamstrahlung quantities are linted an appenale.

The emphasia of this article is on the fundrmental physica of the phonomens during beambeam intercetion. We therefose limit the scope to vingle $e^{t} e^{-}$bunch pairs with hida-on collision. Many important isues, such as kink instability during multi-bunch crosalng [4] and eolliaion at an angle [B], are not discused. Even within the scope of alngle bunch pair beat-on collision, we heve to regrettably limit ouralve to the approximation of decoupling disuption and beamatrahlung. The real isue of beam-beam interaction concerning beamstrahlens with disuption, and disuption with beamstrahlung, are not covered in this lecture. The formar bue has to do with finding a more realistic effective $\boldsymbol{I}$ that includes the pinching of the beam aree, while the latter issue relates to the maximum disroption angles from particles thet ouffor serent radiation. losses. Whth this grand picture in mind, our discussion in this paper should be regarded only as an introduction to the subject of linear collider beum-benm interaction which in vary rich in new phyrics. Throuthout this paper ve adopt the convention $c=n=1$. 


\section{DISRUPTION WITH NEGLIGIBLE BEAMSTRAHLUNG}

Let us recall that the nominal luminosity for head-on collision of two ganssian bunches is

$$
\mathcal{L}_{0}=\frac{N^{2} f_{r}}{4 \pi \sigma_{z} \sigma_{y}}
$$

where $N$ is the number of particles per bunch and $f_{r}$ is the bunch collision rate. When including the disruption effect, the effective beam aren is oraller, which in turn enhances the luminosity. This can be parameterized by a pinch enhancement factor $\boldsymbol{H}_{D}$

$$
\boldsymbol{L}=\boldsymbol{H}_{\mathrm{D}} \mathcal{L}_{0}
$$

In this aection we review the effects of disruption during beam-beam interaction with negligible beamitrahlung energ low.

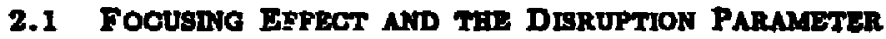

When an electron bunch collidea with s positron bunch, the collective fields from the particles in one oncoming bunch act like a lons to focus the particles in the other bunch toward the axis. The opace charge force from the like particles in the ame bunch it negligible to the accuracy of the order of $1 / \gamma$, where $\gamma$ is the Iorents factor of the relativiatic bunch in the $e^{+} e^{-}$center-of-mion frame. On the contrary, the electric and the magnetic components of the Lorents force provided by the oncoming bunch contribute equally, also up to the accuracy of the order of $1 / 7$, to the focusing fores thet pincher the test bunch.

Let the dennity distribution of a bunch be decoupled for longitudinal and tranverwe cirections:

$$
n(r, z)=n_{2}(z) n_{r}(r)
$$

whese

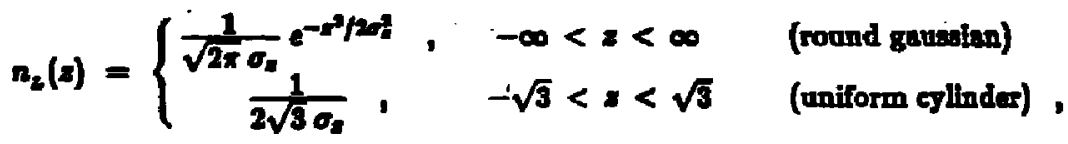

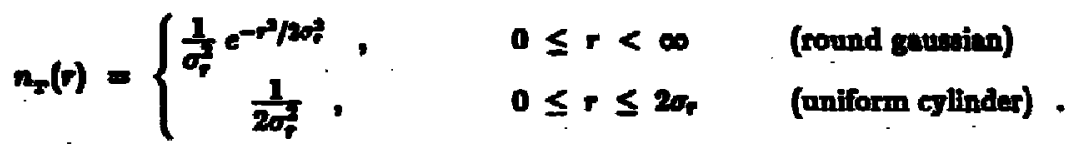


The normalization coefficients are chosen such that $\int n_{s}(s) d s=1$ and $\int n_{\mathbf{r}}(r) r d r=1$. The equation of motion for the test charge in a bunch at coordinate $(r, z)$ is $[6]$

$$
\frac{d r}{d t^{2}}=-\frac{4 r_{c} N}{7} f(r) n_{b}(-2 t-x)
$$

where

$$
f(r)=\frac{1}{r} \int_{0}^{r} n_{r}\left(r^{\prime}\right) r^{\prime} d r^{\prime}
$$

$r_{a}=2.818 \times 10^{-13} \mathrm{~cm}$ is the classical electron rudius and $t=0$ when the centroids of the two colliding bnnehes intereept. Figure 1 i a echeanatic diagram that show definition of the coordinates. Consider, for example, uniform cylinder bunchea. The above equation become

$$
\frac{d r}{d t}+\frac{r_{d} N r}{2 \sqrt{3} N_{r} \sigma_{n}}=0
$$

The eolution it simply

$$
r(t)=r_{0} \cos \left[\left(\frac{r_{g} N}{2 \sqrt{3} \gamma_{p}^{2} \sigma_{s}}\right)^{1 / 2} t+\phi\right]
$$

where to it the impact paramoter of the toot particle upoen antering the targot bumeh and

$$
\phi=\left(\frac{\sqrt{3} r_{0} N \sigma_{s}}{2 \pi \sigma_{r}^{2}}\right)^{1 / 2}
$$

The deflection angle is thatero

$$
\frac{d}{d}=-r_{0}\left(\frac{r_{n} N}{2 \sqrt{3} \eta \sigma_{\mu}^{2} \sigma_{n}}\right)^{1 / 2} \text { in }\left[\left(\frac{r_{c} N}{2 \sqrt{3} \eta \sigma_{\gamma} \sigma_{n}}\right)^{1 / 2} t+\phi\right]
$$

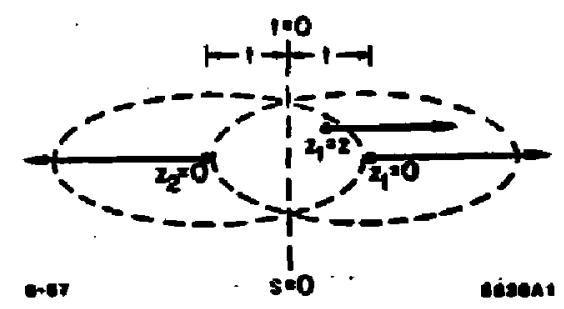

Fi. 1. Behematic diagrem that definea the vrious coordinntes of the two bunches

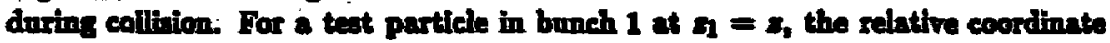
with rejpect to the center of bunch 2 is $z_{2}=-24-s$. 
For a weak deflecting force, at the end of collision $t=\sqrt{3} \sigma_{2}$ we have

$$
\frac{d r}{d t} \sim-\frac{r_{e} N}{\gamma \sigma_{r}^{2}} r_{0}
$$

When the two transverse dimensions have different distributions, i.e., $\sigma_{2} \neq \sigma_{3}$, this exprension can be generalized to

$$
\begin{aligned}
& \frac{d z}{d t} \sim-\frac{2 r_{e} N}{\eta \sigma_{s}\left(\sigma_{2}+\sigma_{n}\right)}=0 \text {, } \\
& \frac{d y}{d y} \sim-\frac{2 r_{d} N}{\gamma \sigma_{m}\left(\sigma_{m}+\sigma_{y}\right)} w_{0} .
\end{aligned}
$$

From say optica the coefficients of equ. (2.8) and (2.9) can be regarded an the inveree of the focal lengths.

We now define a dimentionleas, Lorents inveriant parameter, called disruption parameter $D[7]$, as a mearure of the inverse of foed length in the units of bunch length on in each of the tranoveres dimenaions. The terminology darvived from the fact that during pinching, the beam emittances are severely diarupted. Bxplieitly,

$$
\begin{aligned}
& D_{s}=\frac{2 r_{e} N \sigma_{z}}{\gamma \sigma_{a}\left(\sigma_{z}+\sigma_{n}\right)}, \\
& D_{g}=\frac{2 r_{g} N \sigma_{s}}{\gamma \sigma_{g}\left(\sigma_{g}+\sigma_{\eta}\right)}
\end{aligned}
$$

Let wa further introduce the apect ratio $R \equiv \sigma_{x} / \sigma_{y} \geq 1$, and call

$$
D=D_{y}=\frac{r_{\mathbf{p}} N \sigma_{z}}{7 \sigma_{z} \sigma_{y}}\left(\frac{2 R}{1+R}\right)
$$

Thw, $D_{2}=D / R$. For round beam $(R=1) D_{2}=D_{y}$, and in the aymptotic limit for fint beame $(R>1) D_{*} \approx 0$ and $D \approx 2 r_{e} N \sigma_{z} / 7 \sigma_{z} \sigma_{y}$

For $D<1$, the focusing force is weal enough that each bunch only converges to the axis after traveraing the oncoming bunch; whesen for $D>1$, the foeal point lies well inside the oncoming bunch. Particles experiencing larga values of $D$ would then execute betation oacillations during the course of collision.

To end this divetivion we comment that in the regime where $D \leftarrow 1$, the pinching of the brinches would eamally affect the dioruption for the remainder of the collision. One would therefore naturally think that the parameter $D$ loses its meaning in the quantitative sense. It is fortuitous that actinally $D$ as defined does provide simple ocaling laws as the entre bunch hot a well-defined focal length. 


\subsection{Disetuption ANGLE}

One important information fos linenr collider deign is the expeted disuption angle. Knowl edge on the maximum diaruption anple is esential to determine the aparture of the lut elemant in a final focusing rystem such that it is able to avoid being whowered by the debrit from berm-benm collision.

In terms of $D$, og. (2.T) an be rewritten ax [6]

$$
\frac{d r}{d t}=-\frac{r_{0}}{\sigma_{2}}\left(\frac{D}{2 \sqrt{3}}\right)^{1 / 2} \operatorname{in}\left[\left(\frac{D}{2 \sqrt{3}}\right)^{1 / 2} \frac{t}{\sigma_{t}}+\phi\right]
$$

For $D<1$ and at the time when the teat particle eritifiom the oncoming bunch

$$
\frac{d}{d x} \sim-\frac{r_{0}}{\sigma_{3}}\left(\frac{D}{2 \sqrt{3}}\right)^{1 / 3}\left[(2 \sqrt{3 D})^{1 / 2}+\frac{1}{3 t}(2 \sqrt{3 D})^{3 / 2}+\ldots\right], D<1 \text {. }
$$

For $D \geqslant 1$, at the time of exit from the oncoming bunch teat partlele would have exceuted more then one cyele of betutron cscillation. Therefore, the sinasoldal function in eq. (2.12) is of order unity and

$$
\frac{d r}{d t} \sim-\frac{r_{0}}{\sigma_{s}}\left(\frac{D}{2 \sqrt{3}}\right)^{1 / 2}, D=1
$$

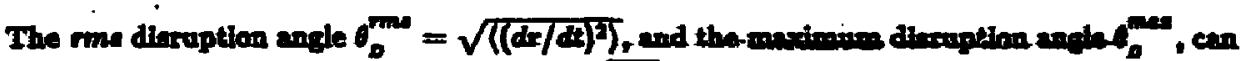
be dedveed from the above equations through $\sqrt{\left\langle r_{0}\right)}$ and $r_{0}$, reopectivels. It b obviowe that in

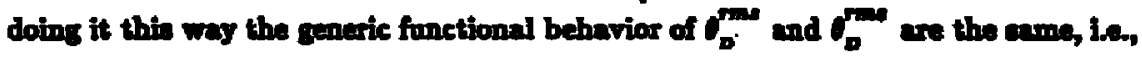

$$
\frac{\theta_{0}}{\theta_{0}} \sim \begin{cases}a+b D, & D<1 \\ \frac{c}{\sqrt{D}}, & D>1\end{cases}
$$

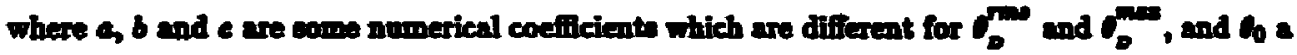
referenee encle defined

$$
\sigma_{0}=\frac{r_{0} N}{\tau \sigma_{r}}
$$

A was dineuned earller, during the colliwion both benms are continuonts deformed due to the mutual phehing. Thos; for reliable estimations of these coeficienta computer ainulations are

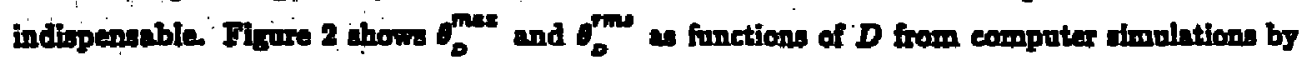

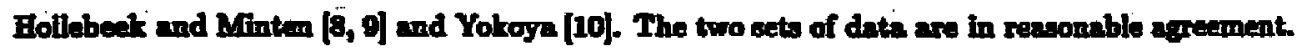




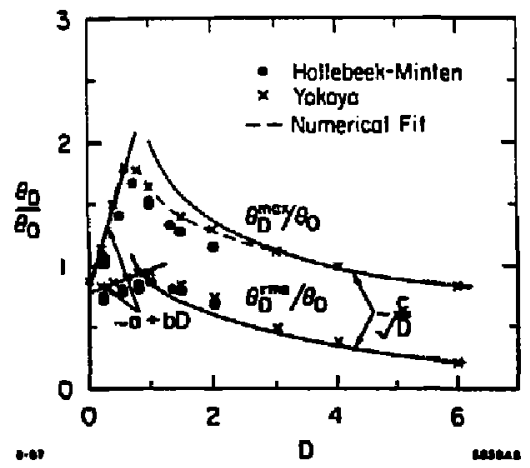

Fig. 2. The maximum and rms disruption angles as functions of D. The solid curves are from eqs. (2.16) and (2.17), and the dashed curve is from eq. (2.18).

From these curves we find

$$
\frac{\theta_{0}^{\max }}{\phi_{0}} \simeq\left\{\begin{array}{ll}
0.087+1.57 D, & D<1, \\
\frac{1.84}{\sqrt{D}}, & D>1
\end{array} .\right.
$$

And

$$
\frac{\theta_{0}}{\phi_{0}} \simeq \begin{cases}0.78+0.20 D, & D<1, \\ \frac{0.67}{\sqrt{D}}, & D>1 .\end{cases}
$$

These arymptotic behavion are shown by solid curves in fig. 2. A different numerical fit which emperically matebes the $\theta_{D}^{\text {mex }}$ data for the entire range of $D$ is given by Palmer [11]:

$$
H_{t}=\frac{1}{\left(\frac{1}{1.2+50 D^{3}}\right)+\left(0.06+\frac{D}{3.38}\right)^{1 / 2}} .
$$

This function is plotted as a dashed curve in the figure.

\subsection{LUMmTOSITY ENHANCEMGNT FaCTOR}

Since the bottom line of an accelerator design is the huminosity, the mort impartant effect of flistuption is the reduction of the effective crows sectional beam area, which caues enhancement of lumirosity. As discused above, this effect can be characterized by the luminosity enhancement factor $\boldsymbol{H}_{D}=\mathcal{L} / \mathcal{C O}_{0}$ where the luminooity is defined as

$$
C=2 N^{2} f \int d x d y d z d t \cdot n(x, y, z-t) \cdot n(z, y,-z-t) \text {. }
$$

$n(x, y, z-t)$ and $n\left(x, y_{1}-z-t\right)$ are the local densities of the two beams at poaitlon $(x, y, z)$ at time $t$. 
To include the disruption effect we return to the equation of motion in eq. (2.4). The solution to the first order in $D$ in [12]

$$
r(t, s)=r 0-\frac{4 N r_{0}}{7} f\left(r_{0}\right) r(t, s)
$$

where

$$
g(t, x)=\int_{-\infty}^{t} d_{1} \int_{-\infty}^{1} d_{2} n_{2}(-2 t-x)=\int_{-\infty}^{t} d_{1}\left(t-t_{1}\right) n_{2}(-x-x)
$$

Thu

$$
r_{0} \doteq r+\frac{4 r_{c} N}{T} f(r) g(t, s)
$$

For on r purpose we like to know the redial distribution function $n$, at $(t, z)$. This can be found by

$$
\begin{aligned}
& n_{-}(t, x)=n_{2}\left(r_{0}\right) \frac{d\left(r_{0}^{2}\right)}{d\left(r^{3}\right)} \\
& =n_{r}\left(r_{0}\right)\left[1+\frac{4 r_{e} N}{\tau} g(t, x) \frac{1}{r} \frac{d}{d r}(r f(r))\right] \\
& =\left[n_{r}(r)+\frac{d n_{r}(r)}{d r} \frac{4 r_{t} N}{7} f(r) g(t, \pi)\right] \cdot\left[1+\frac{4 r_{g} N}{\gamma} g(t, g) \cdot n_{r}(r)\right] \\
& \simeq n_{-}\left[1+\frac{4 r_{n} N}{T}\left(\frac{1}{n_{r}} \frac{d n_{\tau}}{d r} f(r)+n_{r}\right)-g\left(H_{r}\right)\right]
\end{aligned}
$$

With the above exprealon we can estimate the luminosity tomes. (2.19); which can bo be expressed by the bunch coordinates introduced in fie. 1 ,

$$
\begin{aligned}
& c \propto \int \operatorname{ros} d n d n_{2}(n) n_{2}(r)\left[n_{1}(r)\right]^{2}
\end{aligned}
$$

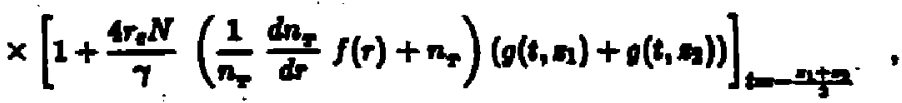

where the leading term corresponds to the nominal luminosity $\mathcal{L}_{0}$. The integration over $r$ can be carried out, which giver -.

$$
\therefore \quad \int_{0}^{\infty} \operatorname{rds} n_{s}^{2}\left(\frac{1}{n_{\tau}} \frac{d n_{t}}{d r} f(r)+n_{r}\right)=\frac{1}{2} \int_{0}^{\infty} \operatorname{rer} n_{c}^{2}
$$

Thus the luminosity enhinesnent factor for on $D$ is

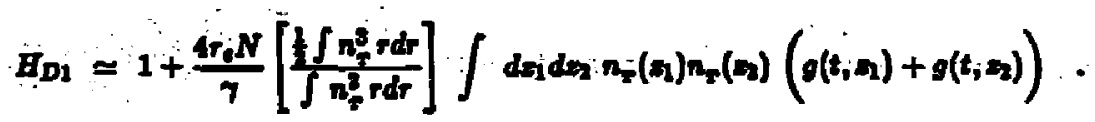


Since the two colliding bunches are symmetric, $g\left(t, z_{j}\right)$ and $g\left(t, z_{3}\right)$ contribute equally to $H_{D}$, where

$$
\left.g\left(t, x_{1}\right)\right|_{t=n_{1}+\infty}=\int_{-\infty}^{t} d t_{1}\left(t-t_{1}\right) n_{2}\left(-2 t-z_{1}\right)=\frac{1}{4} \int_{0}^{\infty} \operatorname{rdr} n_{2}\left(r+x_{2}\right) .
$$

Therefore

$$
\begin{aligned}
& \left.H_{D 1} \simeq 1+\frac{r_{\varepsilon} N}{\gamma}\left[\frac{\int r d r n_{\tau}^{3}}{\int r d r n_{q}^{3}}\right] \int d s_{1} d s_{z} n_{z}\left(s_{1}\right) n_{z}\right)\left(z_{2}\right) \int_{0}^{\infty} r d r n_{L}\left(r+x_{y}\right) \\
& =1+\frac{r_{c} N}{\gamma}\left[\frac{\int r d r n_{\tau}^{8}}{\int r d r n_{r}^{2}}\right] \int_{-\infty}^{\infty} d z \int_{0}^{\infty} r d r n_{x}(z) n_{x}(r+z)
\end{aligned}
$$

Now we introduce norranlised coordinates $\rho=r / \sigma_{\mathrm{r}}$ and $\mathrm{s}=x / \sigma_{\mathrm{m}}$. Then

$$
H_{D 1}=1+D\left[\frac{\int \rho d \rho n_{r}^{3}}{\int \rho d \rho n_{\varepsilon}^{2}}\right] \int_{-\infty}^{\infty} d s \int_{0}^{\infty} \operatorname{rdr} n_{2}(s) n_{2}(r+s)
$$

Plugging in distrubution functions trom eq. (2.3), we obtain

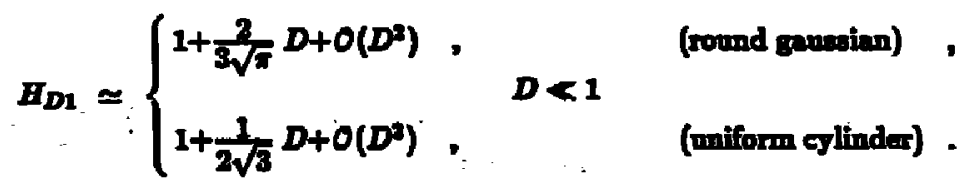

So far the discusion has been linited to round beams. To exterid the above exprewion to arbitrary values of $\boldsymbol{R}$, it is more convenient to rewrite $\boldsymbol{H}_{D}$ as an exponential function:

$$
H_{D 1} \div e^{2 D / 2 \sqrt{n}}, \quad D<1 \quad \text { (round gansion) . }
$$

Reeall thet for diffexint ajpect ration $D$ seales as $2 R /(1+R)[0 t$, eq. $(2.11)]$. So naively one woild tend to asume that $F_{D}(B)$ varies as exp $[2 R /(1+B)]$, which is incorrect.

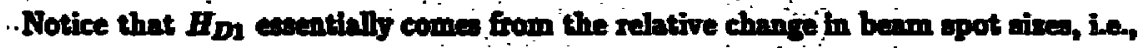

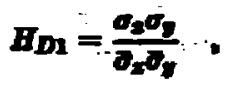

where $4 \pi \sigma_{2} \sigma_{5}$ is the effective bein sirg. Foir round beami

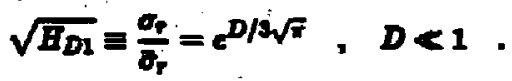


Thus, for $R>1$ we have [eft., eq. (2.II)]

$$
\frac{\sigma_{1}}{\sigma_{1}}=e^{D / 2 \sqrt{r}} ; \frac{\sigma_{3}}{\sigma_{3}}=e^{D / 2 \sqrt{r} R}, D<1
$$

Combining eq. (2.32) and (2.30), we have

$$
H_{D_{1}}(R)=e^{(1+R) D / 2 \sqrt{-R}}, D<1
$$

Now we replace exp $[2 D / 3 \sqrt{n}]$ by $E_{D 1}$, then we obtain

$$
H_{D_{1}}(R)=E_{b_{1}}^{\left(1+B_{1}\right) / 2 R}
$$

This exprection whe firot introduced by Amaldi [3].

Beyond the $D<1$ linit, the diaruption effect becomes very nonlinear and we lack andytic

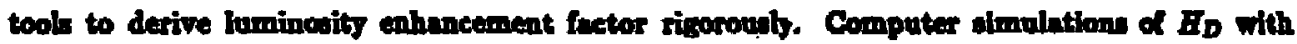

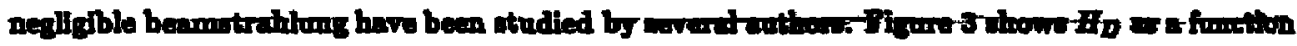
of $D$ for round gansaian beams. The colid curve reprenenti the original worl of Bollabeal [T], where the initivl beam emittanca in sero. The dahed curve b from a recent study by findog

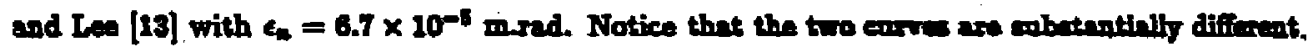

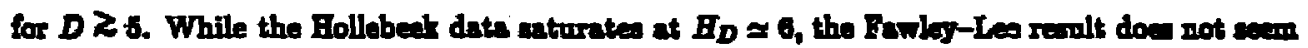

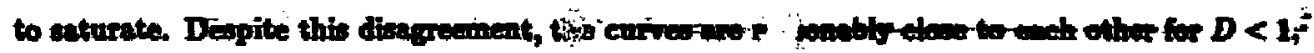
where onr andytic formul in eq. (228) fte quits well :

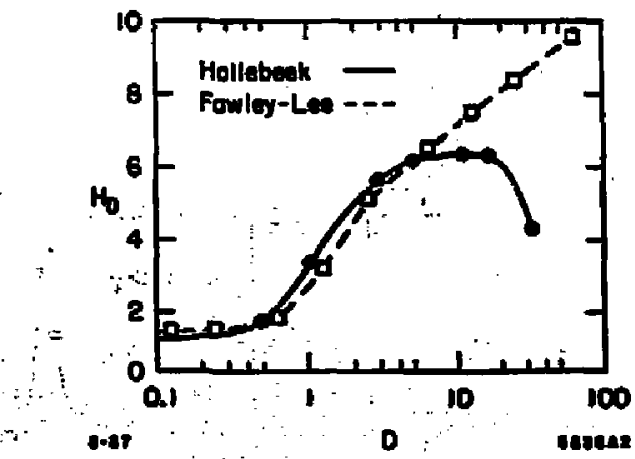

Fic. 3. The lumineots eahancement fuctor $E_{D}$ as a function of $D$. The dits tre taken from the simulation zenlt of Bollebeel, and Faniles and Ioa. 


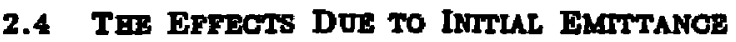

\section{Effect on Lumincoity Enhancement}

In order to have a better aseament of the phyvical process thet contributes to $\boldsymbol{F}_{D}$ beyond the limit of amsll $D$, we invertigate the time evolntion of $H_{D}$ during benm-beam collinion. For this purpoese we singlo ont the time dependence of $\mathcal{L}$ in $\bullet \mathrm{q}$. (2.19) and write

$$
\varepsilon=\int_{-\infty}^{\infty} h(t) d t
$$

The function $h(t)$ in the the "difierential luminosity in time $A$ normalined $h(t)(i . e, h(t) / L)$ was simulationed by Chen ard Yokoja [12]. The hintograms for $D \leq 1$ are shown in fig. 4 .
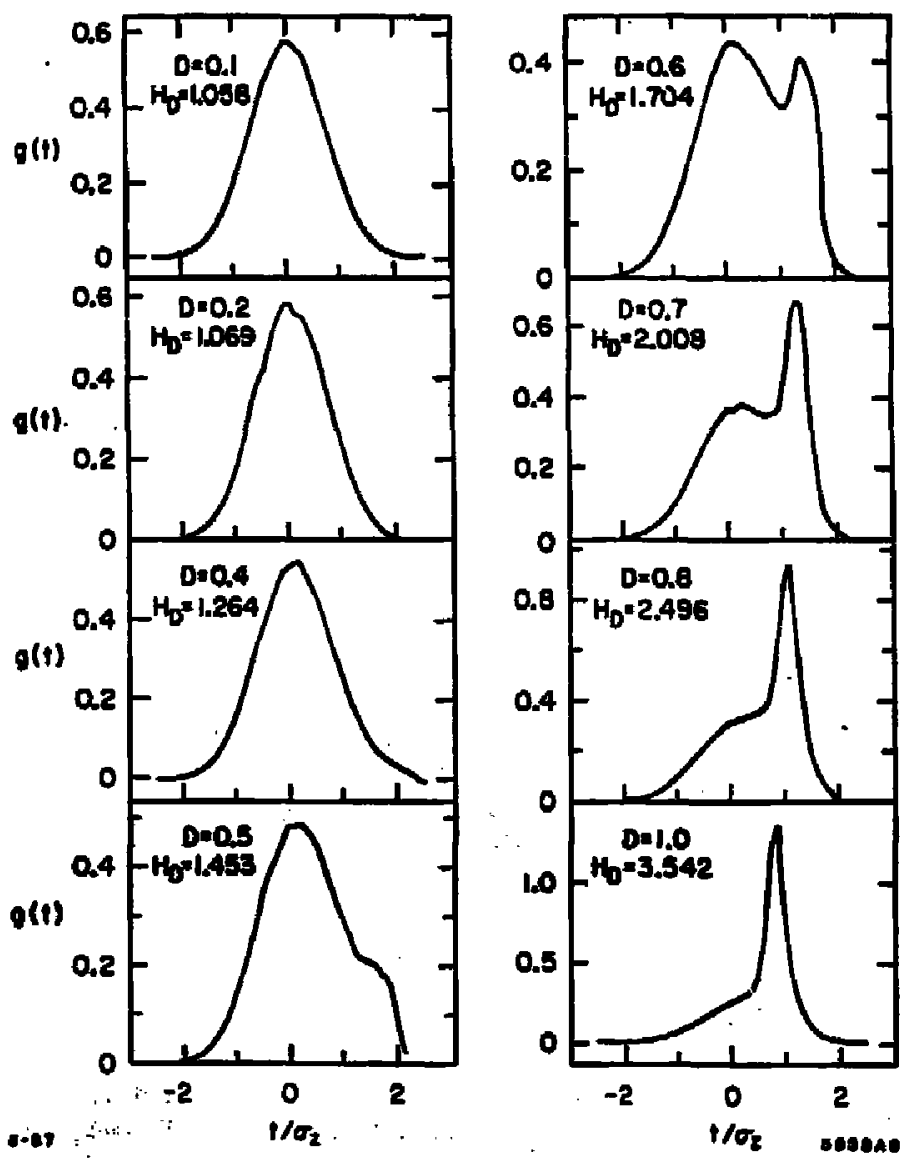

Fig. 4. Computer afmulations by Chen and Yokoye on the time evolution of lumincaiti for different values of $D$. 
From the figures we wee that when $D$ is very amall, eg-, $D \leq 0.5$, the histogram follows essentially as the aquare of bunch-current distribution, which in our cace is gausian. In thie region. of $D$ the enhancement of lumincoity ocenn through the orerall demngnification of the beam croso sections, as discusaed in the previous section, where $H_{D 1}$ in eq. (2.30) agrees reasonably well with the values shown in the first four diagrams in fig. 1, a it should.

When $D \sim 0.5$, a second pesk appears. This is explnined to be caused by particlea at certain radius (not the entire cross section) focteed on beam axis within the oncoming bunch. $A t D=0.5$, this peak occurs at $t=1.5 \sigma_{2}$. The peat grows a $D$ gets larger, and eventully becomen the dominant cource for the luminosity enhancement by $D \sim 1.0$. Notice aleo that the location of the second peak shifts graduslly to the left when $D$ gets larter, whase the atronger disuption induces the phenomenn to occur earlier in time. The ateepnes of thin pent suggests that fing time steps are required in simulation.

Since the second peak is believed to be caused by particlea focused on axis, whero very high denity would occur within a ting volume, we need to fine tune the radinl meah gired in order to avold undarestimating the luminonity at the focal peint. Migare 5 ahow $B_{D}$ a a function

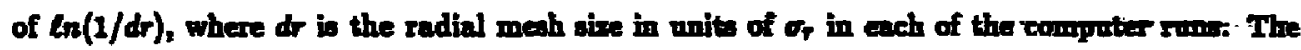
simulation was dape [12] by esouming sero initial emittance for $D=1$ and 1 . It in seen that $H_{D}$ scale conghty finearly a $\ln (1 / d r)$, which in clearly diverzent. This implies that the functional

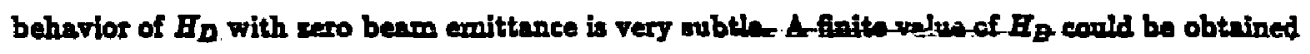
by a.randomly chosen meah aize (or the number of macroparticlex) in a aimulation with zero emittance, but the reoult world not be numerically-etsible-

The symptom for zero emittance beams arises becanse all particlea enter the oncoming bunch in parallel, thus those with the same impact parameter would be focused to a single point. For beams with nonzero initial emittance there would be a mearing effect that this oinguler behevior

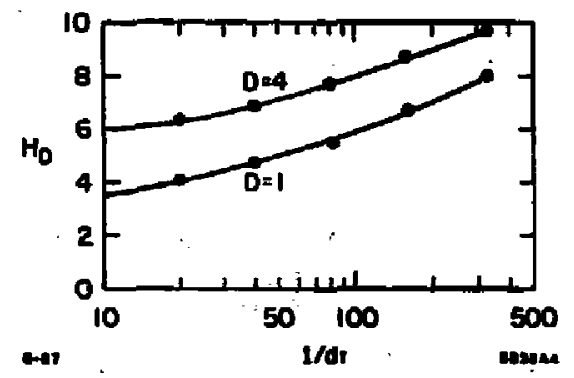

Fig. 5. $H_{D}$ as a function of the inverse of the radial melh sise, $1 / \mathrm{dr}$, in computer simulations for $D=1$ and 4 . The initial emittance is sero. 
can never ocevr. Let w introduce a Lorentz invariant, dimengionleas parameter $A$ that manifests the beam emittance for fxed $\sigma_{s}$ and $\sigma_{y}$ :

$$
A=\frac{\sigma_{\sharp}}{\beta^{0}}=\frac{\epsilon_{m} D}{r_{l} N},
$$

where $\beta^{*}$ is the $\beta$-function at the interaction point. Figure 6 show $B_{D}$ with three different values of $A(A=0.1,0.2$, and 0.4$)$, the aimulation we the computer code $A$ BDL dereloped by Yokoye [14]. As expected, wmaller A gives larger values of $H_{D}$. Furthermort, from the figure we find that

$$
H_{D}(A=.01)-H_{D}(A=0.2) \simeq H_{D}(A=0.2)-H_{D}(A=0.4)
$$

for a given value of $D$, but the eeparation increaces roughly quadratienly. Thin mogents thet the

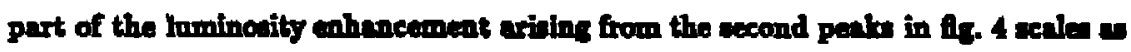

$$
E_{D S} \propto\left[\ln \left(\frac{D}{A}\right)\right]^{2}
$$

From fig. 6 we deduce that

$$
E_{D} \approx \lambda_{1}+\lambda_{2}\left[\ln \left(\frac{D}{A}\right)\right]^{2}, D \geq 1,
$$

where $\lambda_{1} \approx 1.6$ and $\lambda_{9}=0.43$.

Putting everything together, the overall luminonity enhariedment in now

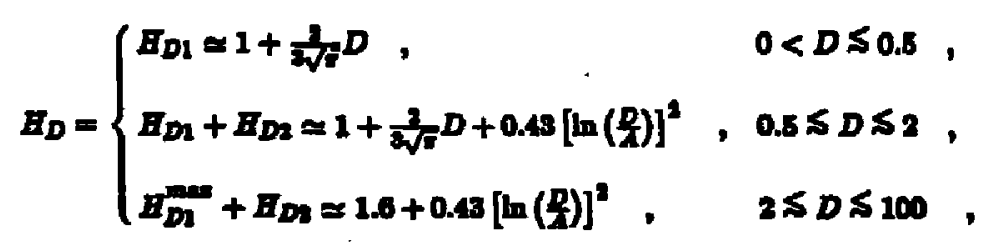

where $\lambda_{1}$ has been Identified to be the anturation of $F_{D}$ at $D \geq 2$, at which vilue the pinehing has induced roughly half a cycle of planmen aveillation [7]. The nonsataration of $B_{D}$ 's in fis. 6 are

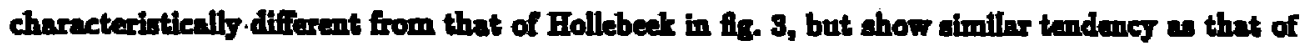
Dawley and Lee.

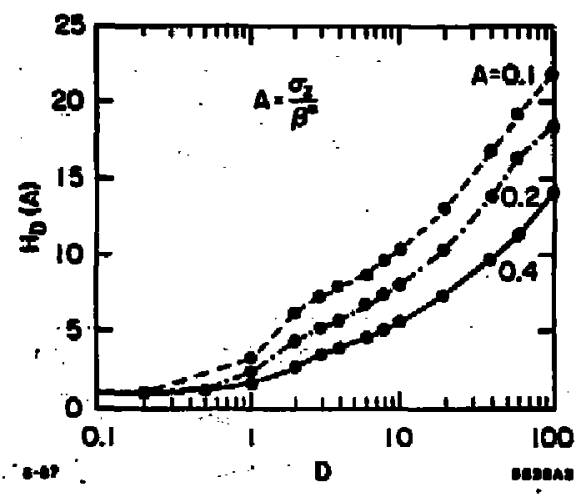

Fig. 6. Inminosity enhancement factor $F_{D}$ with diffacent values of $A$ simnlated by. Chon and Yologe. 


\section{Fffects on Diaruption Angles}

With the dretic impect on luminooity enhneement in mind, it is matural to tol whether the initial emittance aleo mnke large influence on the diaruption andles deweribed in sec. 2.2. Simulations are done by Chen and Yoloya [12] in this respect. Figure 7 shows $\theta_{D}^{\text {mus }}$ and $\theta_{D}^{\mathrm{rm}}$ in the units of $\sigma_{r} / \sigma_{z *}$ Again, $A=0.1,0.2$, and 0.4 are used to find the censitivity of the angles on $A$. The data in the fgure eridently ahow that the dirruption angies are aymptotically independent of $A$. Thus all the statements in sec. 2.2 remain anchnged.

The fact that the diaruption anglea ure independent of $A$ ean be underatood a follows: While luminodity comes from multiplying local dentities of both collidins bunchea, diaruption angles depend oniy on the integrated density of the oncoming bunch (through Ganes's larr). Under thin light the ahurp focus of the litre particles on axi would hwe no aflect on disuption. Purthermore, the Lorents force provided by the oncoming bunch at anj radius $r>0$ would be the sume around the focal point independent of whether the foctis is ahurp or blury.

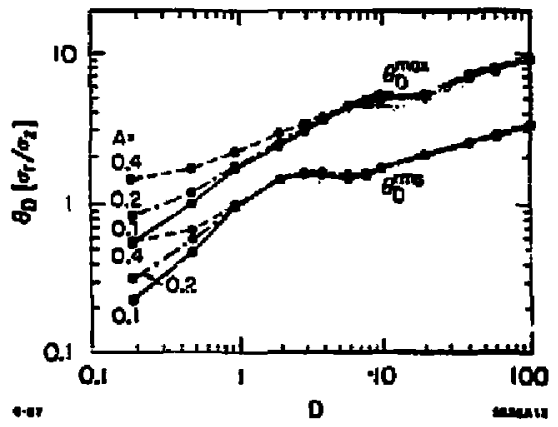

Fit. T. Diesuption angles with different value of 4 simsinted by Chen and Yoloys. 0 's are in the units of $\sigma_{7} / \sigma_{0}$. 


\section{BEAMSTRAHLUNG WITH NEGLIGIBLE DISRUPTION}

In this section we first review the novel characters of beamstrahlung esbuming no bunch deformations. This aerves as an introduction to the more specific discussions following that. To discuss radiation, we take an iterative approach. First we examine the problem with senni-uniform Geld approximation that is auitable for long bunches, from which a beamstrahlung reduction factor $H_{\mathrm{T1}}$ is obtained. Next we include the fact that the field strength in a bunch is actually varying along the trajectory of a radiating particle. This results in a second beamstrahlnng reduction factor $B_{T_{2}}$ when the bunch is short.

With efforts in recent yeara, the understanding of the subject is rapidly maturing, though with a wide apectrum of apposehes to the problem. To be self-eonsistent in our treatment it is dificicilt, if not impossible, to review varions different calculations in detail. Instead we will only mention ench individanl contribution in passing wherever is appropriate.

\subsection{THE NATURE Or BEAMSTBAmUNe}

\section{Collective Fields from Discrete Scattering Centers}

In the laboratory frame (also the center-of-mass frame in our case) of a linear collider, an. electron encountering a poitron with an impact parameter $b$ would heve an effective intercetion time $\Delta t_{1} \sim b / \gamma$ due to the fact that the field asociated with relativintic particles apan abont an opening angle $\Delta \theta \sim 1 / 7$. In torm, the corresponding efiective dintance of maverse throuph the flelds of the oneoming purticle is

$$
\mathbf{L}_{1}=t_{1} \sim \frac{b}{7}
$$

Consider an electron encountering the entire fius of the oncoming potitron bunch. The fiux is roughly

$$
\frac{N}{\sigma_{*}} \equiv \frac{1}{\ell_{2}}
$$

where $\ell_{2}$ is the mean longitudinal sepuration of target particlo. The target benm is considered

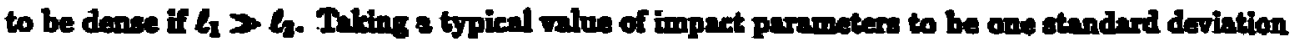

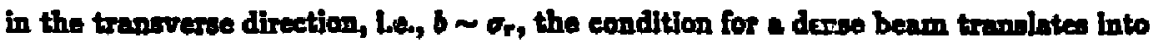

$$
\frac{N \sigma_{1}}{7 \sigma_{2}}=1
$$

In this ease the backerotind field provided by the particle in the oncoming bonch in continuows. (Eee fig. 8.) For example, the Stanford Linear Collider (SLC) beam parameter are $\gamma=1 \times 10^{5}$; number of particles per bupeh $N^{-}=5 \times 10^{10}, \sigma_{2} \sim 1 \mathrm{~mm}, \sigma_{2} \sim 1 \mathrm{~mm}$ at the interaction polnt. This $N \sigma_{r} / \gamma \sigma_{2} \sim 500>1$, and the beam is dense. 


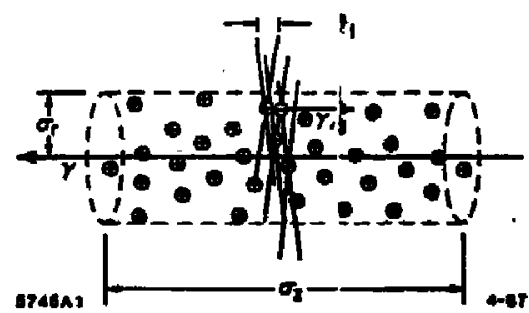

Fis 8. A sehematic diagram for a "dence" beam.

$A$ beam is and to bo divate if $l_{2}<\ell_{1}, \infty$

$$
\frac{N \sigma_{r}}{\gamma \sigma_{z}}<1
$$

In this cace the beckground field becomes diserete and the teat particle would see the granulurity of the target bunch. (See fig. 9.) For example, in the coneeptual acealerator of $5 \mathrm{TeV}+5 \mathrm{TeV}$ discussed by Richter [15], and refined by Himel and Siegrest [16], $7=1 \times 10^{\mathbf{T}}, N=1.2 \times 10^{\mathrm{b}}$, $\sigma_{c}=0.4 \mu \mathrm{m}$ and $\sigma_{\mathrm{p}}=2 \mathrm{~s} \mathrm{~A}$, we have $N \sigma_{\mathrm{r}} f \gamma \sigma_{z} \sim 0.007 \mathrm{~s}<1$. The beam is therefore quite difute.

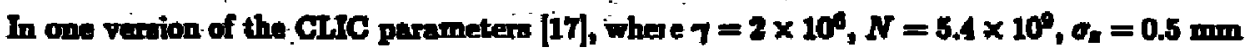

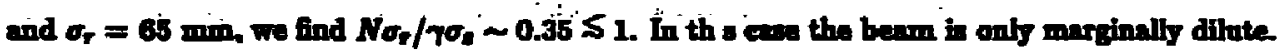

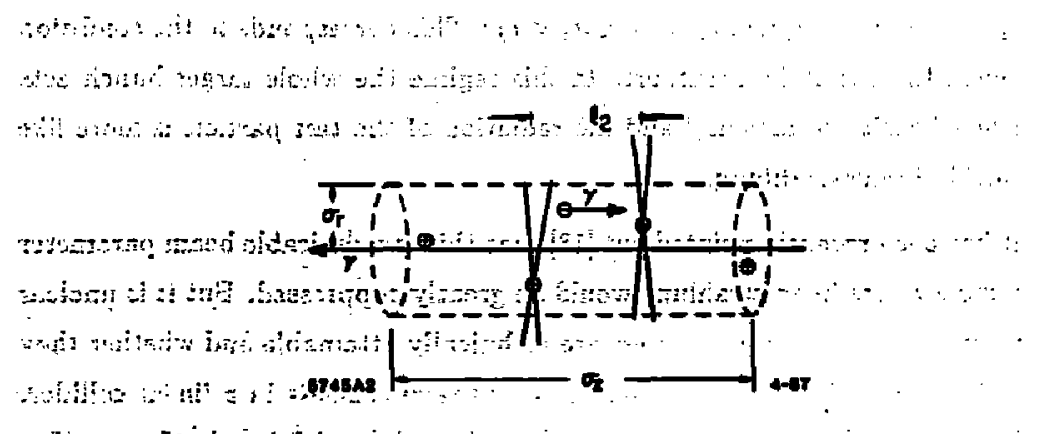

Ifo: $\mathrm{A}$ shamitic dingin for edilute" beam. 
The length scales $\ell_{1}$ and $\ell_{2}$ introduced above arise from kinematic origins. Now we introduce one more length scale, the radiation formation length $\ell_{R}$, which arises from dynamic origin. The radiation formation length is the length which an electron (or a positron) must travel for a photon to be emitted within an open cone with angle $\sim 1 / \gamma$. (More detailed discussion on $\ell_{R}$ is given in sec. 3.2.2.) Together with the bunch length $\sigma_{3}$, the four length scales comprise eight poosible situations, where $\ell_{1}, l_{2}<\sigma_{2}$ by definition. Among the eight arrangements, the cases $\ell_{R}<\ell_{1}<\ell_{2}<\sigma_{I}, \ell_{R}<l_{2}<\ell_{1}<\sigma_{2}$ and $\ell_{1}<\ell_{R}<\ell_{2}<\sigma_{2}$ asolume e chain of close encounters between the test electron and the positrons where each deffection canes a banding nngle of more than $\sim 1 / \gamma$, which is very unlikely. The remaining five craes can be categorised into the following:

a. $C_{2}<C_{R}<b_{1}<\sigma_{n}$ : The bunch is so dense that the teat particle would be bent everaly and quictily lose all it energy. This is a tituation where the accelerator designen would definitely want to avoid.

b. $\ell_{2}<\ell_{1}<\ell_{R}<\sigma_{2}$ (dense beam) and $\ell_{1}<\ell_{2}<\ell_{R}<\sigma_{R}$ (dilute beam): In this xegime the teat electron intenets with tha macroseopic fields collected from poitrons within the range of $\ell_{R}$. For dense benm, the collective fielda within $\ell_{\mathrm{B}}$ ase mooth. The radintion in this case is aimiler to the familiar oynchrotron radiation."

For dilute beams, the interaction with the teat partiele is still collective, but the diverete fieldn would act somowhat lite "undulatos" with menn periodicity $\sim b_{3}$. Theos "undulators" wovid then induce sipple onto a smooth trajetory wapiated with tha menn churge distribution of the target. This would potentially introduce extre radiation. We will discuse thits point in more details Itter.

It occurs that almost all linear collider bem parameter thet people dicused are in this categerg. So the nent of this section will be devoted prtmarily to this case.

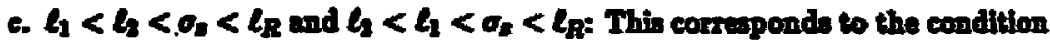
where the bunch is ultanahort. In this regime the whole target bunch acts Ire a "paltron nuelow," and the radiation of the teat particle b mon lite that in becon.trableng.

If hes been reently pointed out [18] that this b a dedirble burm parameter

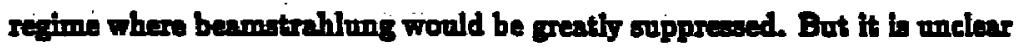
whether anch boam parameters are technically attainabla and whether they will confitet with other stringent phyaical requirumenta in a linear collider. We therefore view it as an interesting option which requires further atudiea. 
Presence of Both Electric and Magnetic Fielda

Unlike a permanent magnet, in beamstrahlung the target bunch presents both electric and magnetic fleld in the $e^{+} e^{-}$center-of-mas frame, whereas in the reat frame of the target bunch there in only F-field. In fect, in our case $\left(|\overrightarrow{\vec{D}}|^{2}-|\vec{B}|^{2}\right) /|\overrightarrow{\vec{D}}|^{2} \sim 1 / \gamma^{2} \geq 0$, and one can never find a frame where there is only B-field.

Facing thi fact, two different approsehes have been thken. One eno either work in the rest frame of the target bunch, which is what Blankenbecler and Drell [19] and Jacob and Wu [20] did, or work in the center-of-wans frame and asmme the Lorents force dwe to $\overrightarrow{\vec{B}}$ and $\vec{B}$ to be equal. This second approach hav been taken by Bimel and Siegrest [16], Noble [21], Yoloye [14, 22] and Chen [23].

Quantum mechmically, in principle, an electron intaracts with $\overrightarrow{\vec{B}}$ and. $\overrightarrow{\vec{B}}$ very diferently. For example, while an electror would execute a circular orbit in a transverse uniform magnetic field, it would intead have an open orbit when traverring a tranvarsa nniform electric field. (Sea fig. 10.) This difference is the genesis of the well-known historical bove called Klein pandox [24] where spontaneou $e^{+} \mathrm{e}^{-}$pair creation is possible when the electron is accelerated in a strong $E$-field.

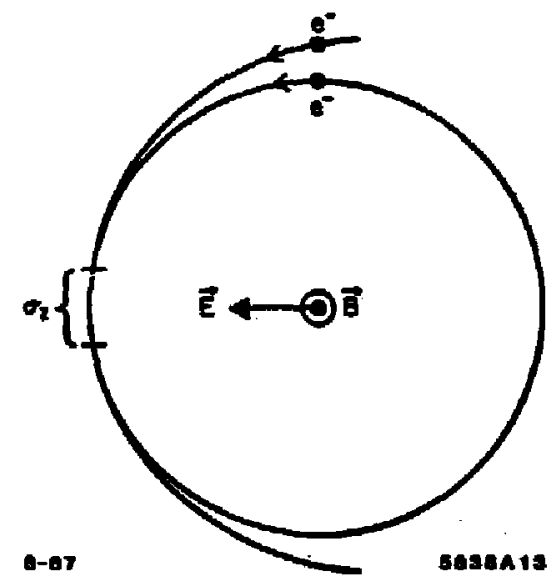

Fif 10. Gosed and open trajectories of an electron under $\vec{B}$ and $\vec{B}$ fields, repectively. For $|\vec{B}|=|\bar{E}|$ the two trajectoriea largely overho around the turning poirt.

Fowever, it is shown by Chen and Noble [25] that beamstrahlong wetually occurs within a very ohort distance $\sim \sigma_{2}$ around the turning point, whese there is-no ewentiel distinction between

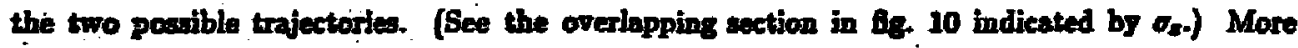
specifically, when the electron momentum which is tranoverse to $\vec{B}$ is much larger than the rest maso; ie, $p_{1}>m$, and when $e|\vec{E}| / m<1$, the radiation rates are the aume from $\vec{E}$ and $\vec{B}$ given equivalent strengths. We will base the rest of our dixcusion of beamstrahlung on this argument. 


\section{Finite Extents of the Fields}

Unlike the bonc fide synchrotron rudiation where the entire closed orbit of an electron is embedded in a uniform magnetic field, in beamstrahlung the fiejd has finite extenta. The strength of the EM field is proportional to the bunch curnent, which typically varies as a gaussian function. Very often an equivalent uniform distribution with total length $L=2 \sqrt{3} \sigma_{z}$ are invoked [Cf., eq. (2.3)] for the suke of mathematical simplicity. A schematic drowing is shown in fig. 11. In the transerse direction, the local field atrength also varies.

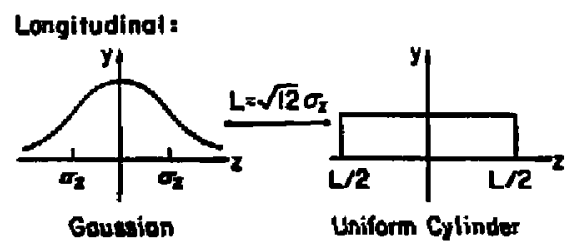

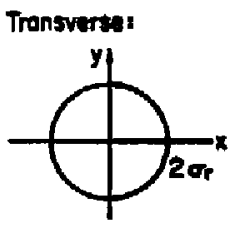

"Round" Bunch

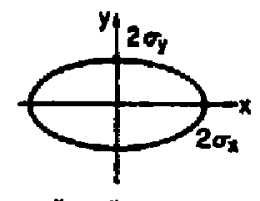

"Flos" gunch

Fig. 11. Sehamatic diagrams of charge diatributions in longitudinsl and transvene directions.

For a round bearn (i.a., $R=1$ ) with a bi-gausgian charge diotribution

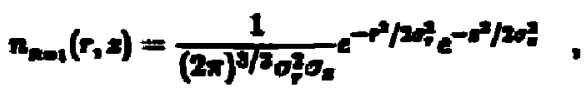

the corresponding field strength is

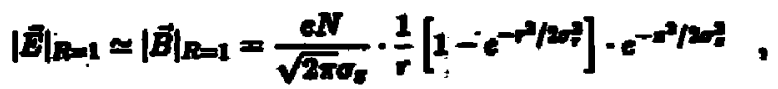

where $\vec{D}$ is in the radial direction and $\vec{B}$ is in the aximnthal direction. In the more generel cese of a flat bean (i.e., $R<1$ ) with a tri-gavoian chnrge dithibution

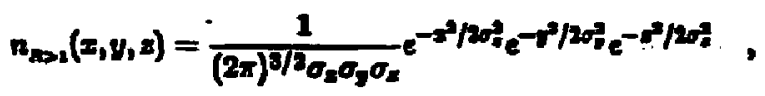

the $\vec{b}$-field is generally not pointing to the radial direction. The field strength is [26] 


$$
\begin{aligned}
& |\overrightarrow{\mathrm{E}}|_{R \rightarrow 1} \simeq|\vec{B}|_{R>1}=\frac{c N}{\sigma_{j} \sigma_{x}} \frac{e^{-\pi^{2} / 2 \mu_{R}}}{\sqrt{R^{2}-1}} \\
& \cdot\left|w\left(\frac{x+i y}{\sqrt{2}\left(R^{2}-1\right) \sigma_{y}}\right)-\exp \left\{-\left[\frac{x^{2}}{2 \sigma_{z}^{2}}+\frac{y^{2}}{2 \sigma_{y}^{2}}\right]\right\} \cdot\left(\frac{x / R+i R y}{\sqrt{2}\left(R^{2}-1\right) \sigma_{y}}\right)\right| \text {. }
\end{aligned}
$$

where $w(s)$ 's are complex error functions.

From eqs. (3.6) and (3.8) it is clear that the fields in a bunch extend only within a faite space with atrengths varying from point to point. Wo lite to atrea, howerer, that their longitudinal variation follows exactly the distribution of the buach charge.

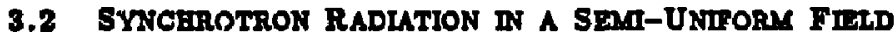

\section{Baler-Kathor Approach}

Ons starting point is the Baier-Katkov method of radintion calculation [27]. 1 aimilnr method had been used earlier by Schwinger [28]. The mothod is baced on the realization that when the radiating particle is ultrarelativistic, its radiation in a magnetic fiald is a quari-clusical problem. By that we mean the motion of an electron becomes more and more clausical a its enerw increases that it makes sense to describe the particle by its trajectory. The redintion in therefore viewed as induced by the bending of the trajectory. The onls role that quatum phyice pley is the noncommutativity between the electron fleld and the photon field, and the conservation of initial and final energies in a discrete manner. The general expresoion of radiation intenolty (in the Coulomb gange) is

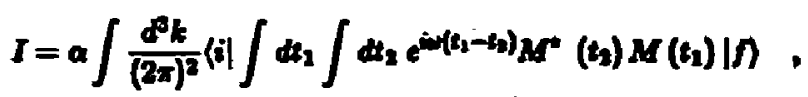

where $a=1 / 137$ is the fine atructure conotant, $(w, B)$ the foriminomentum of the photon, $(d),(f)$ the initial and finel atates of electron, respectively, and $M$ the tranition matric. To the aceurecy of the order of $1 / \gamma$, Baier and Katkor show that the phase fictor from MPM

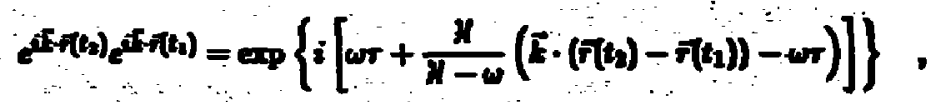

where $r=t_{1}-t_{1}$ and $t=t_{1}+t_{2}$, commutes with both the Familtonian $\mathcal{H}$ and the electron momentuin p. After summing over the spins of the final electron and polarisations of the photon, and averaging over the initial electron spins, the radiation intinsity can be written os 


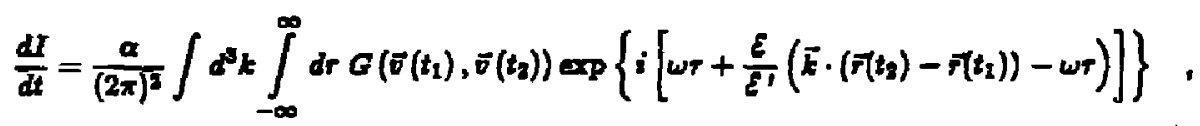

where $\varepsilon$ and $\varepsilon^{\prime}$ are the initial and final energies of the electron and

$$
\begin{aligned}
G\left(\vec{v}\left(t_{1}\right), \vec{v}\left(t_{1}\right)\right)=\frac{1}{4} & {\left[\left(1+\frac{\varepsilon}{\varepsilon^{\prime}}\right)^{2}\left(\vec{v}\left(t_{1}\right) \cdot \vec{v}\left(t_{1}\right)-1\right)\right.} \\
& \left.+\left(\frac{\omega}{\varepsilon^{1}}\right)^{2}\left(\bar{v}\left(t_{2}\right) \cdot \bar{v}\left(t_{1}\right)-1+\frac{2}{\tau^{2}}\right)\right] .
\end{aligned}
$$

From now on we will simplify the notations by designating $v_{1}$ and $\bar{v}_{2}$ for $\bar{v}\left(t_{1}\right)$ and $\bar{\nabla}\left(t_{1}\right)$, repectively. Sirailar notations apply for $\vec{F}(t)$. It is obeerved that the dominnint contribution of the $T$ integation in eq. (3.11) comes from the value at if $\sim 1 / \gamma$. This corresponds to the titutr tion whare the electron poition vector hes awept through an angle $\dot{i} / 7$, or correopondingly the outcoming photon lies within an open cone of angle 1/7. We ahall call this period of time the radiation formation time $r$, and the correaponding distaned of travel by the electron the radiation formation length, $\ell_{R}$. Stince $1 / \gamma<1$ we ean Taylor expand $\vec{v}_{2}$ and $\vec{r}_{2}$ in terms of $\vec{v}_{1}$ and $\overrightarrow{r_{1}}$ :

$$
\begin{aligned}
& \vec{v}_{1} \cdot \vec{v}_{2}=\vec{v}_{1} \cdot\left[\vec{v}_{1}+\vec{v}_{1} r+\frac{1}{2} \vec{v}_{1} r^{2}+\frac{1}{6} \vec{v}_{1} r^{3}+\ldots\right], \\
& \overrightarrow{v^{*}} \cdot\left(\overrightarrow{r_{2}}-\vec{n}\right)=\vec{k} \cdot\left[\vec{v}_{1} r+\frac{1}{2} \dot{\vec{v}}_{2} r^{3}+\frac{1}{6} \vec{v}_{1} r^{2}+\ldots\right],
\end{aligned}
$$

In their papar [27] Baier and Kathov truncated the expansion at $\vec{\nabla}_{1} f_{2}^{2}$, thing the asoumption was

$$
\frac{(1 / 6)\left|\vec{\nabla}_{1}\right| r^{3}}{(1 / 2)\left|\vec{v}_{1}\right|^{2}}<1
$$

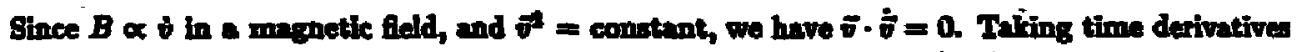
onceesoively, we have

$$
\vec{v} \cdot \overrightarrow{\vec{v}}=-\dot{\vec{v}} \cdot \dot{\vec{v}}, \vec{v} \cdot \overrightarrow{\vec{v}}=-\mathbf{s} \cdot \overrightarrow{\vec{b}}, \text { ete: }
$$

Uding these rolations the asumption an be tranglated into $\dot{B} r / B<1$. Now we define a dimensionleas, Lorents invariant parameter $\mathbf{I}$

$$
\tau=\boldsymbol{\gamma} \cdot \frac{B}{B_{c}}=\frac{\dot{\theta} \gamma^{3}}{\varepsilon}
$$

where $B_{c}=m^{2} c^{3} / e=4.4 \times 10^{33}$ Gavo bi the Schwinger eritical field atrength [28]. The radiation Intensity for electrons in a semi-rniform field satiofying $\dot{B} r / B<1$ ean then be obtalned in terms of $r$ : 


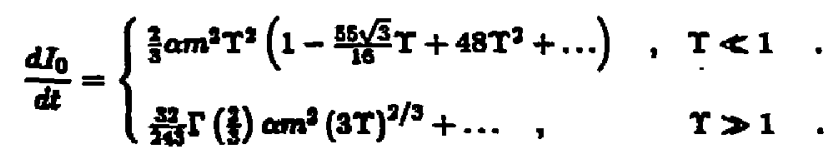

In the above equation the expression for $\mathbf{T}<1$ is the well-known formula for classical synchrotron radiation, including the lading quantum corsection firat derived by Sehwinger [28], and independently by Sokolor, Klepilor end Ternov [29], and hicher terms in $T$. The epreaion for $T>1$ corresponds to tho gychrotion radiation in the extreme quantum limit atudied by many people, but in this article we will simply call it Sololov-Ternov formula [30]. The fact that Baier and Katkov reprodnce these formulas in a streightforward manner and generelize them from atrietly uniform fielda to semi-uniform fields oucoents the power of this method.

\section{Formation Iength and Granularity}

Let us now atpenafiom the above result. The radiation intensity in eq. (3.17) in the total intencity from all powible frequencies. If we look for the powmapectrum $P(\omega)$, definud a

$$
\frac{d T}{d t}=\int_{0}^{\varepsilon} P(\omega) d \omega
$$

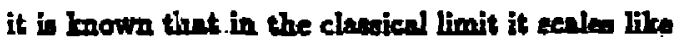

$$
P(\omega) \sim \begin{cases}\omega^{1 / 3}, & \omega S \omega_{e}, \\ \frac{\omega}{\omega_{a}} e^{-\omega / \omega,}, \omega \geq \omega_{e} .\end{cases}
$$

The critical frequency $w_{k}$ in defined weh that the total radiation intensity contributed from $w \leq w_{\varepsilon}$ is equal to that from $\omega \geq w_{e}$. Notice, however, that bighex frequency photons waighted more in termis of intensity. Therefore, the apectrom beyond $\omega_{c}$ doen not cover as lare on aree al that

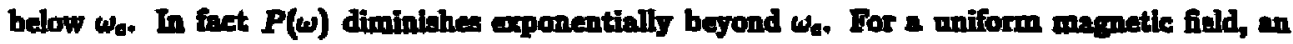
electron would execute s clased orbit with radius $\rho$. The eritical frequency is releted to $\rho$ by

$$
\omega_{c}=\frac{3}{2} \frac{r^{3}}{p}
$$

where trio powas of $\gamma$ comes from Doppler ahif dus to the fect that the relativiotic radiating particle co-moves with the enitted photon. The mis ogening angle of enitted photons at this

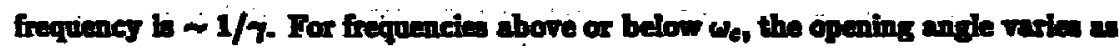

$$
\theta_{\mathrm{rad}} \sim \begin{cases}\frac{1}{7}\left(\frac{\omega_{c}}{\omega}\right)^{1 / 3}, & , \omega 5 \omega_{c} . \\ \frac{1}{\gamma}\left(\frac{\omega_{c}}{\omega}\right)^{1 / 2} & , \omega \geqslant \omega_{c} .\end{cases}
$$


We shall therefore call the corresponding distance of travel of the electron the radiation formation length $\ell_{R}(w)$

$$
\ell_{R}(\omega) \equiv \begin{cases}\frac{\rho}{\gamma}\left(\frac{\omega_{c}}{\omega}\right)^{1 / 9}, \omega \leq \omega_{c} . \\ \frac{e}{T}\left(\frac{\omega_{c}}{\omega}\right)^{1 / 2}, \omega Z \omega_{c} .\end{cases}
$$

The parameter I defined in eq. (3.16) can now be relnted to $w_{e}$ (and therefore $\ell_{R}$ ). From Lorents force $|\vec{F}|=e|\vec{B}|=\mathrm{mm} / \rho$, we have

$$
\tau=\eta \frac{B}{B_{c}}=\frac{\tau^{2} \hbar_{c}}{\rho}=\frac{2}{3} \frac{\omega_{e}}{\varepsilon}
$$

where $\lambda_{\varepsilon}=\mathrm{s} / \mathrm{m} \varepsilon=3.8 \times 10^{-11} \mathrm{~cm}$ is the Compton wavelength. When $T<1$; we find $\omega_{t}<\varepsilon$. In this limit the typical eners of photons is mach amallex then the electron energs and the entire power opectrum of eq. (3.19) is observable. On the other hnd, when $\mathbf{I} \geq 1$, or $\varepsilon<w_{t}$, the apectrum beyond $w=E$ is Inemetieslly forbiddem. So in the quantum limit, only the infrared region of the asoumed elaxical pectrom is obeervable, which scale a $P(\omega) \sim \omega^{1 / 3}$ up to $\omega \simeq \varepsilon$ and $\omega_{c}$ is certainly not to be seen.

Panofsky [31] argued that in a dilute beam, the possible sipples that ruperposed to the smooth trajectory would induce additional radiation analogous to the undulator effect. This radiation introduces a broad spike with mean frequency associsted with the mean particle separation $l_{2}$,

$$
w_{2} \simeq \frac{2 \pi}{4} \tau^{2}
$$

Since $\omega_{\varepsilon} \sim 2 \pi \gamma^{2} / \ell_{R}$, and $\ell_{R}>\ell_{2}$, we have $\omega_{d}>\omega_{c}$. It is thes elear that this pocible grantarity effect is observable only when $I<1$. Bejond the classical regime $w_{C_{1}}$ as well $a w_{c}$, in kinematically forbidden. Thi meens that even though the fields are phycically diverete in a dilute beam, the reiditing particle coly responds to the mein of the fidd variation. This argument has been explicitly confismed by Blankenbecler and Drell [19]. In thil celenlation, the electrontatic potential of each individual target particle (in the ret frame) wes mmmed ap and the fuctuation is shown to be logarithmieally unimportent.

There is, however, an aditional rediation effect due to the compuenlar nature of the target which in independent of whether the beam if ilute or dense. This corresponds to the bremsinahlung from the individual scattering betwean the test electron and the pocitrons (and vice verim) recently colculated by Baier, Kattor and Stral hovengo [3x]. The difference between this effect and the normal bremeatrihlong is that the former is strongly influenced by the mecroscopic beckground field thit we have been divevesing so far. This cubject, however, lies bayond the scope of our article, which deals with the radiation from a particle interacting with the bult part of the-target field only. 


\subsection{SYNCHROTRON RADIATION IN A VARYTNG FELD}

\section{Head-Tail Symmetry and Gausaian Correction}

Consider a magnetic field that points to the direction transverse to the axis where an electron enters, and its strength that varies along the axis. Let $t=0$ when the lectron passen the geometric center of the field. We are intereated in the case where the feld veriation in such that $B(t)$ is an even function in $t$, which is also called head-tail aymmetric. Since from Lorents force $\dot{\delta} \propto B(t)$, we see that $\bar{v} \propto \dot{B}(t)$ is an odd function in $t$. Therefore, in the otudy of radiation from a head-tail symmetric inhomogeneous megetic field, the terms linear in $\bar{v}$ would venish when integrating over $t$. This means the leading correction tarm is of the order $\mathbf{7}$. We ahould thas retain the Taylor expansion in the integrand $G$ op to the term $\overline{\eta_{1}} \cdot \overline{\bar{v}}_{1}$, where the recurrence relation

$$
\vec{v} \cdot \overrightarrow{\vec{v}}=-\mathbf{s} \overline{\vec{v}} \cdot \overline{\vec{v}}-4 \overrightarrow{\vec{v}} \cdot \overrightarrow{\vec{v}}
$$

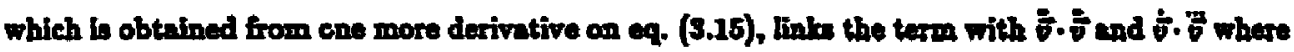
both are even function in time.

As for the phres, retaining terms up to $\overline{\overrightarrow{0}} \cdot \overline{\bar{\theta}}$ we have

$$
\operatorname{ex}\left\{i\left[\omega r+\frac{\varepsilon}{E^{\prime}}\left(\vec{k} \cdot\left(\vec{r}_{2}-\overrightarrow{n_{1}}\right)-\omega r\right)\right]\right\}=\exp \left\{-i\left(\bar{\omega}_{0}+\dot{\varphi}_{1}\right)\right\}
$$

where

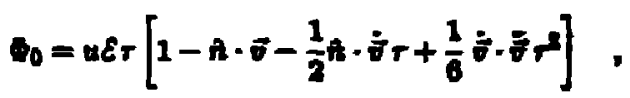

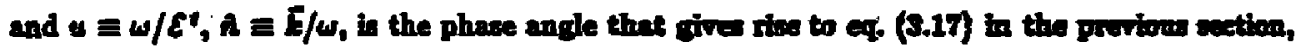
and

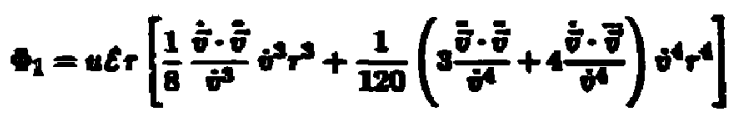

it the additional phose that we retain. Notice that in $\varphi_{1}$ and the lot tern in go we had made the approcimation of repleaing $\mathrm{i}$ by $\bar{v}$.

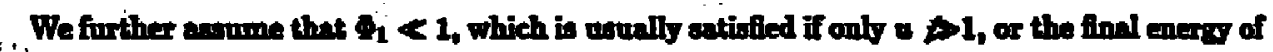

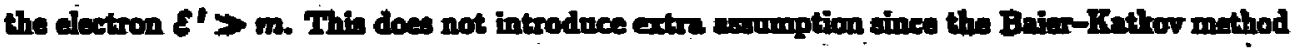
has abeady avomed relativitic electron before and after unitting the photon. Therefore we mike the following appirocimation:

$$
\exp \left\{-i\left(\omega_{0}+\omega_{1}\right)\right\} \simeq\left(1-i \bar{T}_{1}\right) \operatorname{erp}\left\{-i s_{0}\right\}
$$

Retaining terms to the same order in the integrand $G$, and combining with eq. (3.27), we find the integrand to be 


$$
G=G_{0}+G_{1}+G_{2}
$$

where

$$
G_{0}=-\frac{1}{T^{2}}(1+v)-\frac{1}{2}\left(1+v+\frac{x^{2}}{2}\right) v^{2} r^{2}
$$

is the part that reprodvece the Sololor-Tenor formale, $G_{1} \times \dot{B} / B$ in an odd funetion in time and would give sero contribution for hend-tail armmetric feld, and $G_{3}$ is

$$
\begin{aligned}
& G_{2}=-\left(1+ \pm+\frac{a^{2}}{2}\right)\left(\frac{1}{8} \frac{\dot{B}^{2}}{B^{4}}+\frac{1}{6} \frac{\dot{B}}{B^{3}}\right) b^{4} r^{4} \\
& +i \frac{\varepsilon}{120}\left(\frac{1+\psi}{T^{3}}\right)\left(3 \frac{\dot{B}^{2}}{B^{5}}+4 \frac{\bar{B}}{B^{4}}\right) 8^{5} T^{5}
\end{aligned}
$$

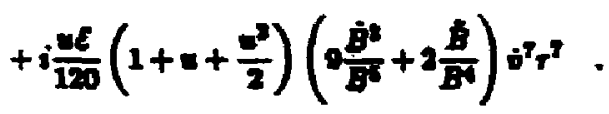

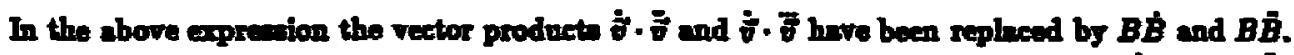
Thi is becawe the onk components the $\overline{\bar{\nabla}}$ and $\bar{\nabla}$ contribete are proportional to $\bar{\nabla} \times \dot{\vec{B}}$ and $\vec{\nabla} \times \overrightarrow{\bar{B}}$, reapuctively.

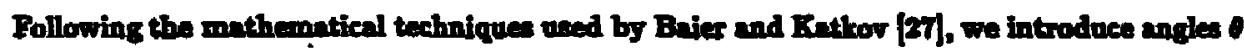
and $\varphi_{1}$.where $i$ the angle between the nnit vector if of photon propagation and the plane $\left(\vec{V}_{\text {, }}\right.$ $\dot{\vec{v}})$, and $\varphi$ the angle between the projection of $f(i)(\vec{v}, \vec{v})$ and $\vec{v}, \mathrm{La}$,

$$
A \cdot \vec{v}=v \cos \varphi \cos \theta, A \cdot \dot{\vec{v}}=\operatorname{\theta in} \varphi \cos \theta .
$$

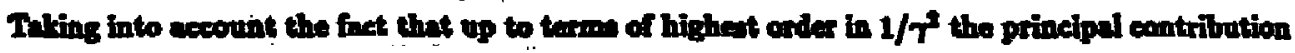

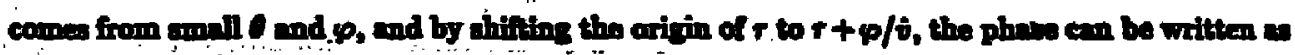

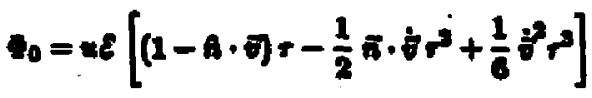

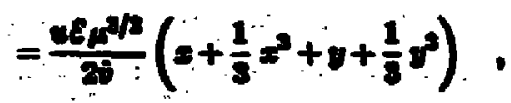

intere

$$
p \equiv 1-\theta^{2} \cos ^{2} \theta \simeq \frac{1}{\gamma^{3}}+\theta^{2}
$$

ind

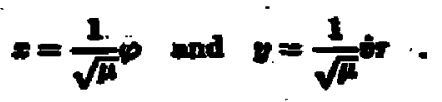


With the definition of $\boldsymbol{Y}$ in eq. (3.16) the coefficients in the phase can be oymbolised by

$$
b=\frac{3}{2} n=\frac{\alpha}{2 I}\left(r^{2} \mu\right)^{3 / 9}
$$

The radiation intenaity umocisted with hoad-teil gymmotric inhomogeneown fleld is then

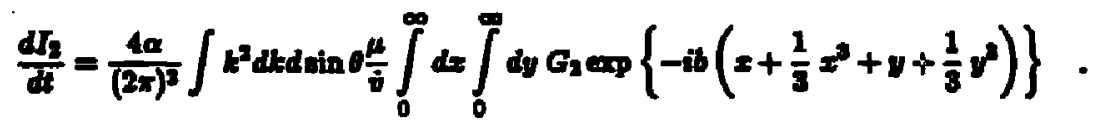

Recall that $y=\omega / \varepsilon^{\prime}=\omega /(\varepsilon-\omega)$, and $k^{2} d t=w^{2} d \omega$, we find that

$$
\omega^{2} d u=\frac{\varepsilon^{2} w^{2} d x}{(1+)^{4}}
$$

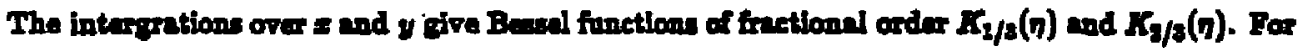

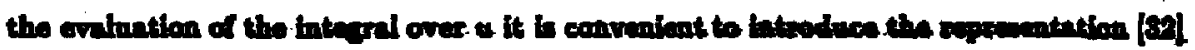

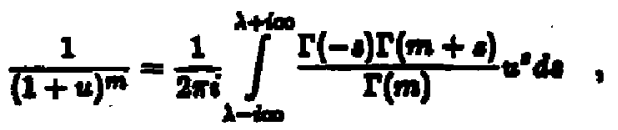

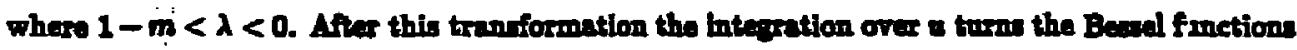
into gamme functions, maltiplied by a fetor $\left(\gamma^{2} \mu\right)^{-2(t+a) / 2}$ amons othe thing. We can then cars out integention over in $0 \approx \theta$ by the following formale

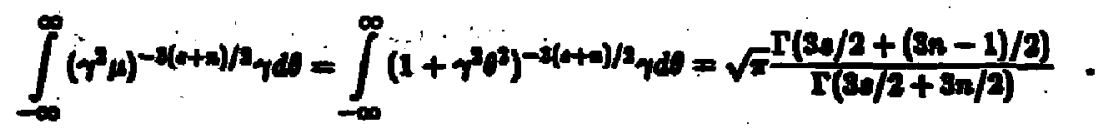

All integrations in eq. (a.39) we otraightorward thouth tediout. Tha rectils before exrying out the final integation orer 8 it 


$$
\begin{aligned}
& \frac{d I_{2}}{d t}=\frac{a T^{2}}{\pi^{3 / 2}} \frac{1}{2 \pi i} \int_{\lambda-i \infty}^{\lambda+\infty \infty} d 2(3 \Gamma)^{0} \frac{\Gamma(30 / 2+1)}{\Gamma(30 / 2+3 / 2)}\left[\frac{\Gamma(0+4)}{\Gamma(4)}+\frac{\Gamma(0+2)}{\Gamma(2)}\right] \frac{\Gamma(-0)}{\Gamma(0+3)} \\
& \times\left\{-\left(\frac{9}{2} \frac{B^{2}}{B^{1}}+6 \frac{\bar{B}}{B}\right)\left[\Gamma\left(\frac{6}{2}+\frac{11}{6}\right) \Gamma\left(\frac{9}{2}+\frac{9}{6}\right) \Gamma\left(\frac{9}{2}+\frac{9}{6}\right) \Gamma\left(\frac{9}{2}+\frac{7}{6}\right)\right.\right. \\
& -\frac{1}{2} \frac{\Gamma(e+3)}{\Gamma(t+2)} \Gamma\left(\frac{2}{2}+\frac{9}{6}\right) \Gamma\left(\frac{1}{2}+\frac{7}{6}\right) \Gamma\left(\frac{1}{2}+\frac{5}{6}\right) \Gamma\left(\frac{6}{2}+\frac{3}{6}\right) \\
& \left.+r\left(\frac{6}{2}+\frac{13}{6}\right) r\left(\frac{6}{2}+\frac{9}{6}\right) r\left(\frac{6}{2}+\frac{9}{6}\right) r\left(\frac{6}{2}+\frac{5}{6}\right)\right] \\
& +\left(\frac{81}{40} \frac{\dot{B}^{3}}{B^{2}}+\frac{2}{20} \frac{\ddot{B}}{B}\right)\left[\frac{256}{3} \Gamma\left(\frac{0}{2}+\frac{11}{6}\right) \Gamma\left(\frac{6}{2}+\frac{9}{6}\right) \Gamma\left(\frac{0}{2}+\frac{9}{6}\right) \Gamma\left(\frac{0}{2}+\frac{7}{6}\right)\right. \\
& +\frac{224}{3} r\left(\frac{1}{2}+\frac{13}{6}\right) \Gamma\left(\frac{6}{2}+\frac{9}{6}\right) \Gamma\left(\frac{6}{2}+\frac{9}{6}\right) \Gamma\left(\frac{0}{2}+\frac{5}{6}\right) \\
& -\frac{128}{6+8} \Gamma\left(\frac{9}{2}+\frac{15}{6}\right) \Gamma\left(\frac{6}{2}+\frac{13}{6}\right) r\left(\frac{1}{2}+\frac{11}{6}\right) \Gamma\left(\frac{5}{2}+\frac{9}{6}\right) \\
& \left.\left.-\frac{216}{9}(0+2) \Gamma\left(\frac{1}{2}+\frac{9}{6}\right) \Gamma\left(\frac{6}{2}+\frac{7}{6}\right) \Gamma\left(\frac{2}{2}+\frac{5}{6}\right) \Gamma\left(\frac{6}{2}+\frac{3}{6}\right)\right]\right) \text {. }
\end{aligned}
$$

where $-1<\lambda<0$. The above exprewion includes only contributions from the $v^{4} r^{4}$ and $\dot{v}^{7} r^{7}$ terms in eq. (3.29) becawe it can be shown that the contribution from the ${ }^{6}{ }^{5}$ term is aignifieantly amallet, and thus negligible.

The integral over a can be eveloated by closing the contont of integration either to the right for $I<1$, or to the left for $T>1$. For $T<1$, wa hava

$$
\frac{d I_{2}}{d t}=0, I<1 \text {, }
$$

identically. Tor $I>1$ we hive to the leading order in $r$,

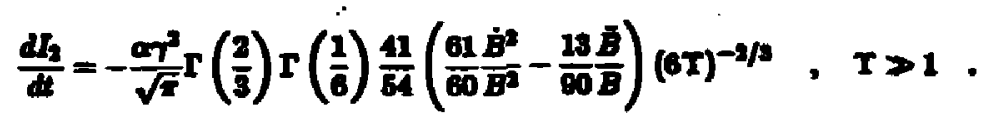

Thi reolt is valid for ang hosdotail armmotric inhomogeneou magnetic field which antiffiea the asumption given previonsily:

Now wa apply eq. (3.38) to the feld from a relativistic gaudian bunch with atandard deviation $\boldsymbol{\sigma}_{\mathbf{7}}:$

$$
B(\theta)=B_{0} e^{-x H}
$$

where the the of flight of the tent electron traverving the oneoming bunch in $t=z / 2$. Then we get 


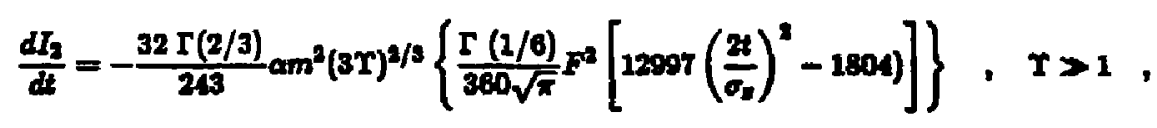

where $F \equiv \ell_{R} / \sigma_{2}$ in the formation leagth paramoter avocinted with $\ell_{R}(\omega)$ in the quantum limit for photon frequency $\omega=\varepsilon$ :

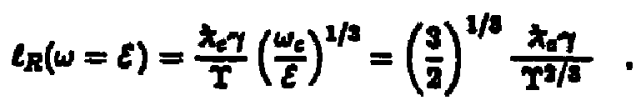

Combining equ. (3.37) and (3.40) with eq. (3.17), wo obtaln

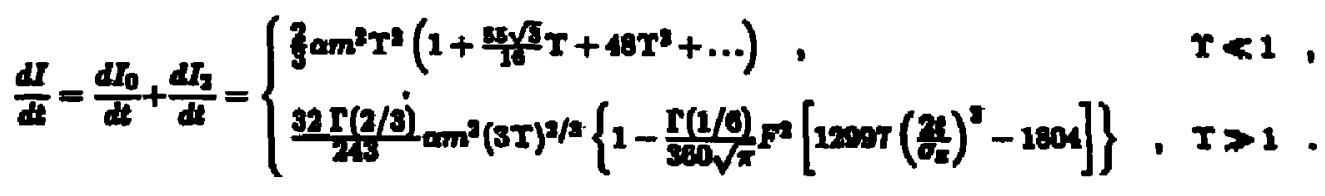

Short Mergnets and Rediation Reduction

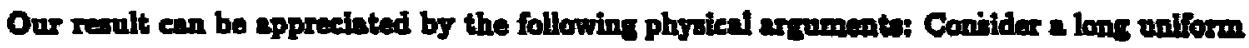

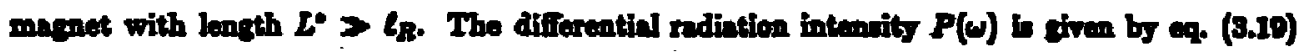
and shown by the solid curve in fig. 12. As in introduced in eq. (32s), clacical linit $\mathbf{T}<1$ corresponds to the situation $w_{e}<\varepsilon$, meaning the typieal freguenes of radiated photons to much lew than the kinetic energs of the radiating particle. This the entive epectrum of eq. (3.10) is observable. On the contrary, the extrene quantum limit $I>1$ corroponds to $\varepsilon<w_{c}$, thasufore the epectrum beyond the electron energ is binematically forbidden, and the obuerveble ryectrum seales roughly as $\omega^{1 / 9}$ as diecused earlier. This cut-of in ahown by the vertical dashed lir.e in the firne.

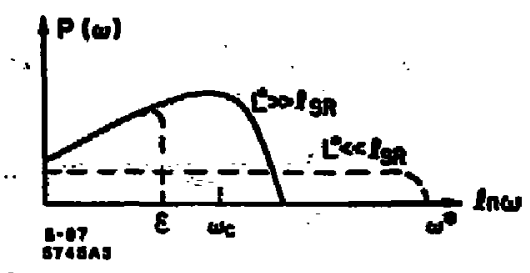

Fis. 12. Radiation opectrum in the tro agmptotle limit. For long magneta, $L^{*}>\ell_{R}$, we have the well-known apectrum in the eolid curve, In the oppoite limit $L^{*}<\ell_{R}$, the opectrum eppronches a constant. In quantum limit we obterve only the bow frequency regime. 
. In the case of nonuniform fields the spectrum differs from that of uniform fields. For the rlassical limit the problem has been studied by Coisson [33], and independently by Bagrov, Fedosov and Ternor [34]- It is found that for a short magnet which is comparable in length with $\ell_{R}$, the radiation spectram is modified in such a way that the low-frequency regime is suppressed in favor of high frequencies beyond $\omega_{c}$. The total intenrity, however, remuins the anme. The prediction wes confirmed by Bossart ef al. [35] with observations in SPS at CWRN. We can extrepolate this fect by auggeating that when the magnet length $I^{*}<\ell_{R}$, the epectrum would be a contant independent of $\omega$ up to a maximum frequency $\omega^{*} \sim \omega_{e}\left(l_{R} / L^{*}\right)$ (aes the horicontal dashed curve in fig. 12). Our result for the elsurical limit shows that the total intensity $d r / d t$ is the same for uniform and gausian field. This is a confirmation of the previous atudies.

The aitustion for shost magnets is different in the quantum limit. Again, apectrom bejond $\mathcal{E}$ is energetically forbiddan. Bat now that the low frequency regime is auppressed, the overall intensity is reduced. This explains why our $d I_{2} / d t$ is opponito in sige from $d I_{0} / d t$. From eq. (3.49) it ean be seen that when $l_{2}<\sigma_{n}$, or when the bunch is very long, $d I_{2} / d t \rightarrow 0$, and we have vaniahing corroction to the Sololov-Ternov formula. $\boldsymbol{A}$ pronouneed efiect occurs when $\ell_{R}$ is not mech omaller than $\sigma_{\text {g. }}$

\subsection{REDUCTION OF QUANTUM BEAMSTRAHLING}

\section{Fint Beamstrahlung Reduction Fector}

With the radiation intensities derived in previow sections, we are now resdy to estimate the average enersy low during beaw-bean collioion. Individual ete- acatterings are neglected, and the target bunch acts only to provide a macroccopic field. For the Eate of arguments, we will in this section asume s hobri "tylindrical ganaian" bunch, it.,

$$
\begin{cases}n_{k}=\frac{1}{\sqrt{2 \pi \sigma_{\theta}}} e^{-r^{2} / 2 \pi}, & -\infty<x<\infty \\ n_{r}=\frac{1}{2 \sigma_{r}}, & 0 \leq r \leq 2 \sigma_{r} .\end{cases}
$$

It If atmightforwerd to ahom that the loeal field strength in this case is

$$
|\vec{B}|_{R=1}=\frac{\alpha N}{2 \sqrt{2 \pi \sigma_{p}^{2} \sigma_{x}}} r e^{-s^{2} / 2 \pi}, 0 \leq t \leq 2 \sigma_{p}
$$

The above expreaion b identian to eq. (3.6) when the approcionntion of $r<0$ is taken. We now introduce nomnlived coordinntes as in sec. 2.3 ,

$$
\rho=\frac{r}{\sigma_{r}}, s=\frac{s}{\sigma_{z}},
$$

then we can define a local benmotrahlung parameter 


$$
T(p, x)=T_{0 \rho e^{-x / 2}}
$$

where

$$
T_{0}=\frac{r_{e} \lambda_{c} \Gamma N}{\sqrt{2 \pi} \sigma_{p} \sigma_{a}}
$$

iv the reference beamatrahlung parameter corresponding to twice the field etrength at $(\rho, \zeta)=$ $(1,0)$ in the target burch.

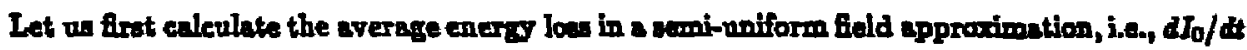
in eq. (3.17). The validity of this asumption for a gaupinn current distribution is that the bunch is very long; hence, the fild strength changes mildly,iec, Br/B $<1$. Foquivilently, if a uniform cylinder bunch in invoked, this implies that the end efiect are neqlected.

Iat

$$
\epsilon=\frac{\varepsilon-\varepsilon^{\prime}}{\varepsilon}
$$

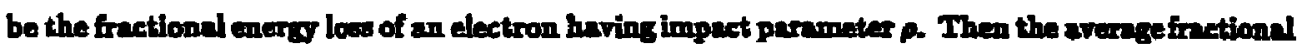
energy low of the entise buneh is

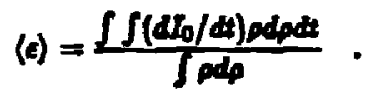

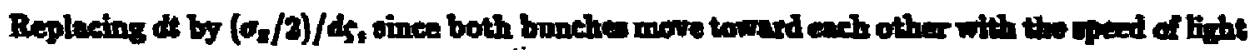
$(c=1)$, and define

$$
\Gamma_{0} \pm \frac{t_{c \boldsymbol{T}}}{\sigma_{\boldsymbol{n}}}
$$

we find for the clapical limit

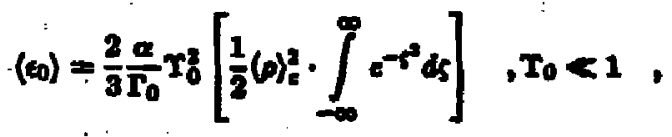

where the elowied mern rathe is

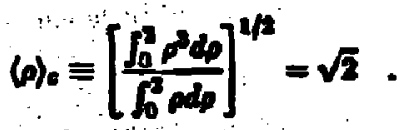

On the of thes hand, for the guantum limit

$$
\left(c_{0}\right)=\frac{32 \cdot \Gamma(2 / 3)}{2 / 3} \frac{\alpha}{\Gamma_{0}}\left(3 T_{0}\right)^{2 / 3} \cdot\left[\frac{1}{2}(0)^{3 / 3} \cdot \int_{-\infty}^{\infty} e^{-1 / 3} d s\right], T_{0}>1
$$

where the quantom mean radius is 


$$
6\rangle_{0}=\left[\frac{\int_{0}^{2} \rho^{8 / 3} d p}{\int_{0}^{2} \rho d \rho}\right]^{3 / 3}=2\left(\frac{3}{4}\right)^{3 / 2}=1.30 .
$$

Notice that the geometric form factore in the two limita are surprisingly clase:

$$
\frac{1}{2}(\rho)_{0}^{2} \cdot \int_{-\infty}^{\infty} e^{-r^{2}} d s=\sqrt{\pi} \simeq \frac{1}{2}(\rho)_{t}^{2 / 3} \cdot \int_{-\infty}^{\infty} e^{-r^{2} / 9} d s=1.03 \sqrt{x} .
$$

Anuming from now on the same geometric form fartor $\sqrt{x}$ in both limits, we then have extremely simple sealing lawe for the areract fractional energ bos in beamitrahlung:

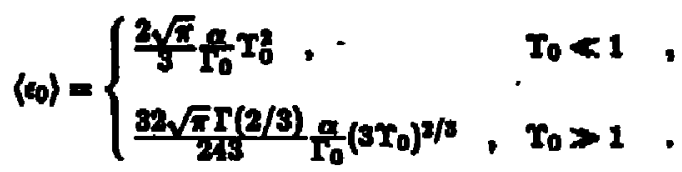

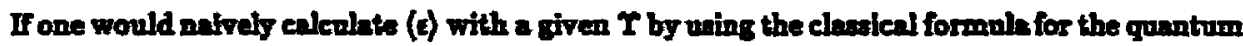
regime, he would obtain moaninglealy largo reoulta before uiing the correct quantum formula. A beamstrahlung "reduction" fetor $F_{r l}$ is thus introduced to account for the change, which is the ratio of the bottom eprovion to the top expreasion in eq. (3.83):

$$
\lim _{T_{0 \rightarrow \infty}} E_{T 1}\left(T_{0}\right)=\frac{16 \Gamma(2 / 3)}{81} \mathbf{r}_{0}^{-1 / 3}=0.080 T_{0}^{-1 / 3}
$$

while

$$
\lim _{T_{0 \rightarrow 0}} E_{\mathbf{T 1}}\left(T_{0}\right)=1
$$

If is remiachble that thit beamotrahlung reduction fuctor is execty what ono would got by

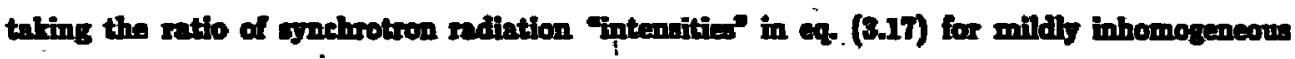
fields, with $T_{0}$ a en effective beametrahluing parameter representing the entire bunch. This is the case only because the geometric form fictor does not viry too much in the two limits. It can be shown that this is true oren for the transition regime 0.1 S I0 $S$ 100, where we lukt a timple analytic acaling $\mathrm{hm}$. A numation plot for the entire range of $\mathbf{I}$ given by When [2] b shown in fig. 13.

In the titerature $[21$, ] ] these b an eficetive beamatrahlung paraneter $\overline{\mathrm{I}}$ defined based on computer sinnlation with gaveian bunches,

$$
I=\frac{5 r_{e} \lambda_{e} N}{12}\left(\frac{3 \sqrt{R}}{1+L}\right)
$$




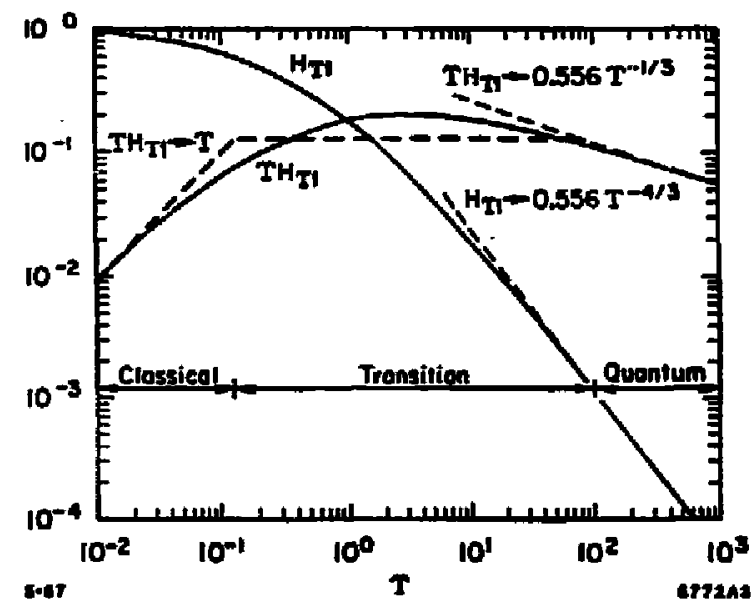

Fis. 13. The beamatrahlung reductlon tietor $E_{X_{1}}$ and the product $T E_{X_{1}}$ ar a function of the cealing parameter $T$, plotted by P, B. Wileon.

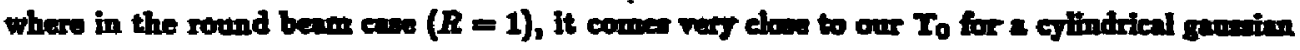
bunch,

$$
\frac{\bar{T}}{T_{0}}=\frac{5 / 12}{1 / \sqrt{2 \pi}} \simeq 1.04 \text {. }
$$

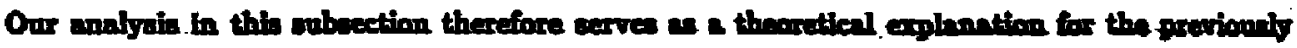
known facts. Notice, howeves, that our axpreaviona in eq. (3.53) have conceptually aimplified the description: No effective radiation time [2] is necesary, and $\Gamma_{0}$ in deflned in atraightforward way without extra numetical facion [21].

\section{Second Beametrahlung Reduction Factor}

As discussed in the earlier sections, the Sololov-Ternor formula does not include thie effect due to the fast variation of the field atrength along the particle's trajectory. The correction term derived in see. 3.3 [A., eq. (3.42)] indicatie that there is an additional beamstrehlung rednetion.

To include the conrection term we should realien that our perturbation breals down before

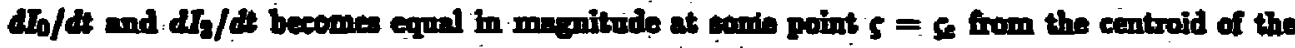
bunch, beyond which the total intensity would turn negative and be certinnly unphysical. Since we lack the knowledge on the behavior of higher order terms, we can only extimate the upper bound of the reduction offect by extending $d I_{2} / d t$ all the wey to $\xi_{c}$ and asouming totel suppreasion beyond that point, as ahown schematically in fig. 14. From eq. (3.42) this threahold oceurs at

$$
\frac{\Gamma(1 / 6)}{360 \sqrt{\pi}} F_{0}^{2} P^{-1 / 2} e^{22 c^{2} / 3}\left(12997 \xi^{2}-1804\right)=1 \text {, }
$$




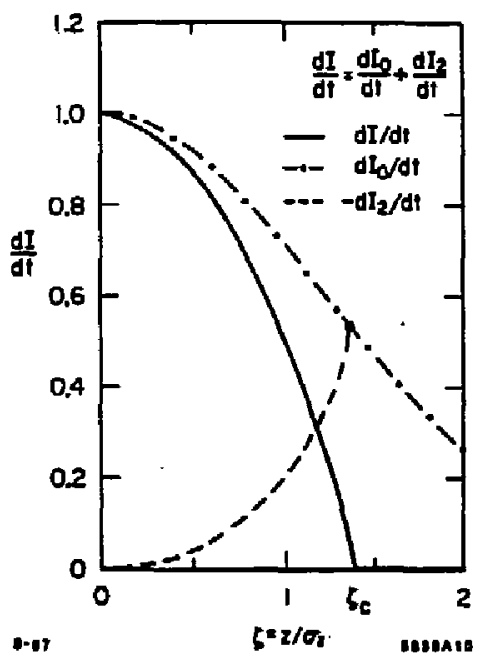

Fis. 14. Radiation intennition as function of longitudinal target bunch coordinate 5 . The dash-dot curve in the Sololor-Ternor radiation. The dash curve is the negative of our gaussian slope correction. The net intensity is represented by the solid curve. Beyond the point $\zeta_{e}$ where $d I_{0} / d t$ and $-d J_{2} / d t$ meet, we assume a total suppresaion.

where

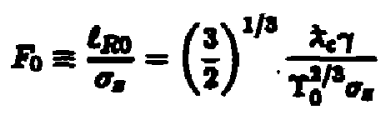

in the reference radiation formation length parameter associnted with $\boldsymbol{T}_{0}$, and is relnted to $F$ by

$$
F(0,5)=F_{0} \rho^{-2 / a_{e}} / \mathrm{a}
$$

From eq. (3.57) it in obvious that the eut-ofi $\varsigma_{e}$ is radial dependent. For the oake of aimplicity in our diacuesion, we mnke a further approximation by evaluating $\zeta_{e}$ at the menn impact parameter $\langle 0\rangle_{q}=1.30$. Thus the mean radiation lose is suppressed to

$$
\left(s_{50}=\left(\epsilon_{0}\right\rangle_{50}+\left(\epsilon_{2}\right)_{50}\right.
$$

There

$$
\left(c_{0}\right)_{50}=\frac{3 \cdot \Gamma(2 / 3)}{249} \frac{\propto}{\Gamma_{0}}\left(3 T_{0}\right)^{2 / 3}\left[\frac{1}{2}(0)^{2 / 3} \cdot \int_{-\infty}^{-T / 3} d s\right]
$$

and

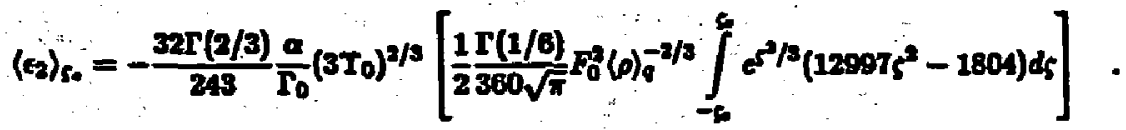


Let ws define the second beamstrahlong reduction factor $H_{12}$ as the ratio of eq- (3.60) to the quantum formula in eq. (3.51):

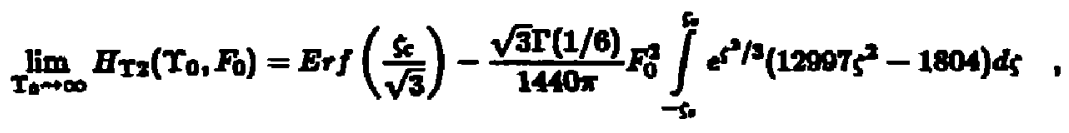

where Brf is the error function and

$$
\lim _{T_{0 \rightarrow 0}} E_{\mathrm{T} z}\left(T_{0,} F_{0}\right)=\lim _{\Gamma_{0 \rightarrow 0}} F_{T_{2}}\left(T_{0,} F_{0}\right)=1
$$

With this lengthy expression, it is hard to apprecinte the importance of the reduction. As a sumerical example, let us take the beam parametero discussed by Himel and Siegreat [16], namely, the Lorents factor for $5 \mathrm{TeV}$ beams $\gamma=1 \times 10^{7}$, number of particle per bunch $N=1.2 \times 10^{\circ}$, bunch sire $\sigma_{z}=0.4 \mu m$ and $\sigma_{r}=2.5 \mathrm{~A}$. With these parameters we find

$$
\mathrm{I}_{0}=\frac{r_{i} \lambda_{\mathrm{e}} \mathrm{N} N}{\sqrt{2 \pi \sigma_{r} \sigma_{\varepsilon}}}=5094>1
$$

and the reference formation length parameter

$$
F_{0}=\left(\frac{3}{2}\right)^{1 / 3} \frac{\hbar_{e \gamma}}{T_{0}^{2 / 3} \sigma_{x}}=\frac{0.015 \mu \mathrm{m}}{0.4 \mu \mathrm{m}}=0.0375 \text {. }
$$

The cut-of ge at the mean impact parameter $(p)_{Q}=1.30$ turng out to be

$$
\varsigma_{\epsilon}=1.49
$$

Plugting in numbers we get

$$
\left\langle\epsilon_{0}\right\rangle_{S_{0}}=0.78\left\langle\epsilon_{0}\right\rangle_{\infty}=11.8 \%
$$

and

$$
\left\langle\epsilon_{2}\right\rangle_{50}=-0.11\left(\epsilon_{0}\right)_{\infty}=-1.6 \%
$$

Thas the corrected quantum beamstrahlung average fractional energy loas in

$$
\text { (c) } Z(c)_{6}=10.9 \% \text {. }
$$

This is substantially afferent from the previous results. The second reduction factor in this case is

$$
H_{12}=\frac{(\epsilon)}{\left(\epsilon_{0}\right)}=0.67
$$

or rednced from the semi-uniform field approximation by a fector of $\sim 2 / 3$. 
Although our diseussion on $\boldsymbol{B}_{\mathrm{T}}$ has been limited to the extreme quantum limit, it is rensonable to aseume that this reduction effect occums to the trantition regime as well. Based on the arguments given in sec. 3.3.2, the effect of a ahort buich is to ruppress the epectrum below $\omega_{c}$ and strotch it to frequencies beyond $w_{c}$. By definition $T=2 w_{c} / 3 E$, wo for $T$ an amall as $\approx 1$ the kinetic energy already lies below $\omega_{c}$ and we should expect to see the second reduction.

To conclude, we showed that the average fractional energ loss can be related to the elasical anchrotron radiation formule with the reference beamstrahlung parameter $I_{0}$ as an effetive parameter and

$$
\langle c\rangle=\frac{2 \sqrt{\pi}}{3} \frac{\alpha}{\Gamma_{0}} T_{0}^{2} \cdot E_{\mathrm{T} 1} \cdot E_{T 2}
$$




\section{APPENDIX \\ QUANTUM FLUCTUATIONS IN BEAMSTRAHLUNG}

In this Appendix we liat varions beumstrahlung quantities of interent to high energy physics and accelerator design. The finetuation in these quantities arisen from the fect that bypical number of radiated photons per electron during beam-benm interaction is owall in the quantum regime, and not very large (of order everal) even in the classical regime like the case of SLC.

Analytic formulas have been derived by Yokoye [22] on the everage number of photons radiated per electron $\left\langle N_{7}\right\rangle$, the average fractional energs loss $\langle e\rangle$ defined in eq. (3.48), the standard deviztion of $E$ :

$$
\sigma_{\mathrm{a}}=\left\langle\epsilon^{2}\right\rangle-\left\langle\boldsymbol{\varepsilon}^{2}\right.
$$

the average fractional seduction of the centar-of-man enero $W=s^{1 / 3}=2\left(E_{1} \varepsilon_{2}\right)^{1 / 2}$ of two particles in beam 1 and beam 2 at some apace-time point:

$$
(w)=\left(\frac{W_{0}-w}{W_{0}}\right)
$$

and the standard deviation of $w$ :

$$
\sigma_{w}=\left\langle w^{2}\right\rangle-\langle w\rangle^{2}
$$

Following the same opirit, Noble [21] has investigated, in addition to the above quantities, also the average fractional center-of-mass energy squared reduction:

$$
\langle s\rangle=\left(\frac{s_{0}-s}{s}\right)
$$

and its standerd deviation:

$$
\sigma_{a}=\left(\sigma^{2}\right)-(\theta)^{2}
$$

in computer aimulations. Durthermore the average photon eners is introdnced as

$$
(\mathbf{n})=\left\langle\frac{\omega}{\varepsilon}\right\rangle
$$

Table 1 lifts the formulas obtained by the two anthors, whore

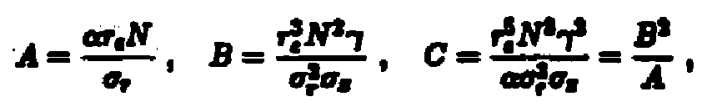

and

$$
Q=\frac{\alpha^{4}+N^{2} \sigma_{L}}{7 \sigma_{5}^{2}}
$$

The functions $h(T)$ and $g(T)$ are liated in Table 2 for various vilues of $\bar{T}$, and the coeficients $a_{1}$ $a_{2}, b, d_{1}, d_{j} ; d_{3}$ for (A) $\mathbf{S} 0.1$ are listed in Table 3 . In all cases no diaruption is asumed. 
Table 1

Formulas for qunntum flectantion on verious physical quantities derived by Yologe analytically, and dedaced by Noble through computer simulation.

\begin{tabular}{|c|c|c|c|}
\hline & \multicolumn{2}{|c|}{ Yolroya } & Noble \\
\hline & $I<1$ & $I>1$ & All I \\
\hline $\begin{array}{r}\left\langle N_{\eta}\right\rangle \\
\langle\Omega\rangle\end{array}$ & $1.0597 \mathrm{~A}$ & $1.554 Q^{1 / 3}$ & $\begin{array}{l}\frac{5}{2 \sqrt{3}} \frac{\alpha}{\Gamma} h(\bar{\Upsilon}) \\
\frac{1}{5 \sqrt{3}} \frac{a(\widetilde{Y})}{h(\tilde{Y})}\end{array}$ \\
\hline$\langle\bar{c}$ & $\begin{array}{c}0.2164 \theta \\
0.4048\langle\varepsilon\rangle\left(1+\frac{31.30}{\left\langle N_{7}\right\rangle}\right)^{1 / 2}\end{array}$ & $\begin{array}{c}0.395 Q^{1 / 3} \\
0.193\langle\epsilon\rangle\left(1+\frac{61.80}{\left(N_{7}\right)}\right)^{1 / 2}\end{array}$ & $\begin{array}{c}\frac{2}{3} \frac{a}{\Gamma} g(\mathrm{~T}) \\
a_{1}(\epsilon)\left(1+\frac{a_{2}}{\left(N_{7}\right)}\right)^{1 / 2}\end{array}$ \\
\hline $\begin{array}{l}(w) \\
\sigma_{\infty}\end{array}$ & $\begin{array}{c}0.4094\langle c\rangle \\
0.3146(s)\left(1+\frac{10.04}{\left(N_{n}\right\rangle}\right)^{1 / 2}\end{array}$ & $\begin{array}{c}0.458(\epsilon) \\
0.205(\epsilon)\left(1+\frac{13.20}{\left(N_{7}\right)}\right)^{1 / 2}\end{array}$ & $\begin{array}{c}b\langle c\rangle(1+\langle\Omega)\rangle \\
d_{1}\langle\varepsilon\rangle\left(1+\frac{d_{2}}{\left\langle N_{\gamma}\right\rangle}\right)^{1 / 2}\end{array}$ \\
\hline$\langle b\rangle$ & & & $2 d_{1}\langle\varepsilon\rangle\left(1+\frac{d_{3}}{\left\langle N_{7}\right\rangle}\right)^{1 / 2}$ \\
\hline
\end{tabular}

Thble 2

Representative values of the function $g(T)$ and $h(T)$ in the range $10^{-8} \leq \bar{T} \leq 10^{3}$.

\begin{tabular}{|c|c|c|}
\hline$\overline{\mathrm{T}}$ & $g(\mathrm{~T})$ & $h(\overline{\mathrm{T}})$ \\
\hline $10^{-3}$ & $9.91 \times 10^{-7}$ & $9.99 \times 10^{-9}$ \\
$10^{-2}$ & $9.45 \times 10^{-5}$ & $9.91 \times 10^{-3}$ \\
$10^{-1}$ & $6.55 \times 10^{-3}$ & $9.30 \times 10^{-2}$ \\
1 & $1.82 \times 10^{-1}$ & $7.16 \times 10^{-1}$ \\
10 & 1.84 & 424 \\
$10^{2}$ & $1.11 \times 10^{2}$ & $2.13 \times 10^{1}$ \\
$10^{3}$ & $5.56 \times 10^{2}$ & $1.01 \times 10^{3}$ \\
\hline
\end{tabular}

\section{Tablòs}

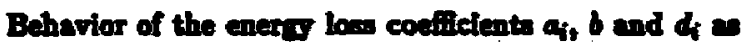
a function of the biam ridintion parameter $\overline{\mathbf{I}}$ when (c) So.1.

\begin{tabular}{|c|c|c|c|c|c|c|}
\hline $\bar{x}$ & $a_{1}$ & $a_{2}$ & $b$ & $d_{1}$ & $d_{2}$ & $d s$ \\
\hline $510^{-2}$ & 0.41 & 30 & 0.42 & 0.32 & 10 & 10 \\
$10^{-1}$ & 0.38 & 30 & 0.43 & 0.31 & 10 & 10 \\
1 & 0.31 & 33 & 0.44 & 0.27 & 14 & 10 \\
10 & 0.25 & 43 & 0.45 & 0.24 & 18 & 11 \\
$10^{2}$ & 0.22 & 53 & 0.46 & 0.22 & 22 & 12 \\
$Z 10^{3}$ & 0.20 & 63 & 0.47 & 0.21 & 26 & 13 \\
\hline
\end{tabular}


$\bar{I}$ is defined in eq. $(3.55) \mathrm{as}$

$$
\bar{T}=\frac{5}{12} \frac{r_{e} \hbar_{e} N}{\sigma_{8} \sigma_{3}}\left(\frac{2 \sqrt{R}}{1+R}\right) \simeq I_{0} .
$$

The rymbol $\Gamma$ is reluted to orr $\Gamma_{0}$ leq. (3.49)] by

$$
r=\frac{9}{16} \frac{\lambda_{c T}}{\sigma_{2}}=\frac{1}{\sqrt{\pi}} \Gamma_{0}
$$

i.e., the grometric form factor $\sqrt{\pi}$ bas been aboorbed into $r$.

More recently, Amildi [B] introduces simple sealing lam that rensonably reproduce the formule in Table 1:

$$
\begin{aligned}
(c) & \simeq\left(\frac{4}{5}\right)^{2} 2 \frac{a}{\Gamma_{0}} \vec{T}^{2}\left(1+\bar{T}^{1 / 2}+\frac{3}{2} \bar{T}\right)^{-1 / 8}, \\
\left(N_{T}\right) & \simeq 2(c)\left(1+\bar{T}^{1 / 2}+\sqrt{\pi} \bar{T}\right) / \bar{T}, \\
(n) & \simeq \frac{1}{2} \bar{T}\left(1+\bar{T}^{1 / 2}+\sqrt{\pi} \bar{T}\right),
\end{aligned}
$$

and

$$
\sigma_{0}=\frac{1}{\theta}\langle c\rangle\left(2+e^{-\bar{T} / 3}\right)\left[1+\frac{10+\sqrt{3} \ln (10 \bar{T}+I)}{\left\langle N_{7}\right)}\right]^{1 / 2} .
$$

\section{DISCLAIMER}

This xteport was prepared as an acootunt of thork spowsoned by ath apency of the United States Govonment. Noilber the Uuited States Government nor any agancy thereof, nor any of their employees, males any warranty, express or implied, or assumes any legal fiability or responstbility Ior the aceuracy. completences, or mefoliness of any information, apparatus, product, of procese tisclosed, or represents that its use wond not infringe privitely owned rifters Reference herein to any speelific commercial product, process, or service by trade name, tradenart. manufacturer, or ollherwise des not nocessarily constitute or inply its endarsement, reom. meodation, of favoring by the United Stales Government of any agency thereof. The vieus and opiaions of aulhors expressed hercin do not necrosarily state of reflect those of the Uaitod Sentes Cowernment if any agency theroot. 


\section{RFPATNCTS}

1: SLC Design Fand book, SLAC, Stanford, CA (Dec. 1984); SLAC-Report-299 (Jume 1980).

2. P. B. Wiloon, SLAC-PUB-4310 (My 1887).

3. U. Amaldi, Nuel. In. Moth. A24s, 312 (1986).

4. Y. E. Chin, DDSY Rejeart (1887).

5. This ides wes recently nurgeted by $R$. Palmer.

6. K. Yoloye, private communications.

7. R. Hollobeak, Nuch In. Moth. 184 (1081).

8. R. Hollebeak and A. Minten, SLAC Internal Report, GN-301 (June 1985).

9. A. Minten, SLAC Internal Report, CN-305 (June 1985).

10. I. Yoloys, BLAC Intanal Report, AAB-27 (March 1987).

11. R. Pabmer, StuAC Intarnal Roport, $M A B-30$ (1087).

12. P. Chen and K. Yolsore, 8LAC-PUB-4359 (1987).

13. W. M. Fawley and F. P. Ioo, Lawxence Livermore National Laboratory Beport (1987).

14. X. Yologa, KaT Report ak- (1895).

15. R. Bichter, IFHE Tran. Nuel. Bei. NE-32, 3828 (1905).

16. T. Fimel and J. Siegreat, Loew Aceelention of Partieles, eds. C. Joahi and T. Kateouleas, AIP Conf. Proc. No. 130 (18s5).

17. W. Schnell, G3RN-LBP-BS/86-06 and CLIC Note 13, 1986. The parameters atated in our paper is a recent modifieation by Sehnell.

18. P. Chen, in Physics as Future Acederators, ed. J. Mulves, CDRS 87-07, Vol. I (1987).

19. R. Blartrenbecler and 8. D. Drall, Phye. Bev. D 86, 277 (1987).

20. M. Jacob and T. T. Wu, CDRN-TE/87-61 (1987).

21. R. J. Noble, STAC-PUB-3871 (1986), to appear in Nrel. Inot. Moth.

22. K. Yokoya, Hucl. Int. Meth. A261, 1 (1986).

23. P. Chen, SLAC-PUB-1391 (1987), to appear in the Proceading of the Workshop on Net Developments in Potide Acederution Techniques, Orsay, France (June 1987).

24. F. Klein, Zeitechrift der Phyoik 58, 157 (1920).

25. P. Cherr and R. J. Koble, SIAC-PUB-4050 (1986).

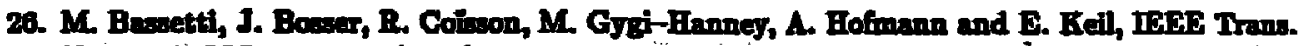
Nucl. Sci. $198-80,2182$ (1983).

27. V.N. Baier and V. M. Katkow, Soviet Phys. JETP 26, 864 (1938); and Soviet Phys. JETP 28, 807 (1989).

28. J. Schwinger, Proe. Itational Acaderny of Sci. 40, 139 (1054).

29. A. A. Sololop, N. P. Klepitor and I. M. Temov, Soviet Phy. Dollady, 80, 665 (1953).

30. A. A. Sololov and I. M. Tarnor, Synehrotron Radiation, Perganom Preas (1937).

31. W. Punofily privati comminientions (1985).

32. V. N. Baier, V. M. Katkor and V. M. Stralchorealo, INP-Novosibirs $87-26$ (1987).

39 R Coswon, Opties Comm 29, 135 (18m) and Phys. Rer. A.20, 624 (1079).

34. V. G. Bagrer, N. I Dediod and L. M. Tanow, Phys. Rer. D 28, 2484 (1883).

35. R. Bowart, 3. Bow, I. Burnod, R. Coinoon, E. D'Amico, A. Fofinann and J. Mann, Nuel. Inat. Meth. 104, 374 (1079).

38. U. Amalal, CFtar-FP/87; in these Proceedingo. 